\title{
Exploring Harm Reduction Among Canadian Veterans Experiencing Homelessness
}

Olivia Marsella, The University of Western Ontario

Supervisor: Dr. Cheryl Forchuk, The University of Western Ontario

A thesis submitted in partial fulfillment of the requirements for the Master of Science degree in Nursing

(C) Olivia Marsella 2018

Follow this and additional works at: https://ir.lib.uwo.ca/etd

Part of the Psychiatric and Mental Health Nursing Commons

\section{Recommended Citation}

Marsella, Olivia, "Exploring Harm Reduction Among Canadian Veterans Experiencing Homelessness" (2018). Electronic Thesis and Dissertation Repository. 5545.

https://ir.lib.uwo.ca/etd/5545

This Dissertation/Thesis is brought to you for free and open access by Scholarship@Western. It has been accepted for inclusion in Electronic Thesis and Dissertation Repository by an authorized administrator of Scholarship@Western. For more information, please contact wlswadmin@uwo.ca. 


\begin{abstract}
BACKGROUND: The use of substances is substantially higher among people experiencing homelessness than the general population (Podymow, Turnbull, Coyle, Yetisir, \& Wells, 2006). In Canada, veteran homelessness is an increasing concern and it is estimated that there are 2,950 veterans experiencing homelessness (Gaetz et al., 2016). Furthermore, veterans often use substances, particularly alcohol, to cope with the transition from the military to civilian life (Ray \& Forchuk, 2011). A strategy that has been shown to reduce the negative harms of substance use and facilitate housing stability is harm reduction (MacNeil \& Pauly, 2010). Exploring how veterans who have experienced homelessness perceive harm reduction may provide further information to properly address this group's unique housing and health needs.
\end{abstract}

METHODS: This study was a secondary analysis on data collected from The Canadian Model for Housing and Support of Veterans Experiencing Homelessness study, which evaluated a veteran-specific housing model in four Canadian cities including Calgary, London, Toronto, and Victoria. In total, 78 veterans participated in the primary study and qualitative data was collected via focus groups with veterans, staff, and stakeholders in three cycles at each of the four sites from 2012 to 2014 (Forchuk \& Richardson, 2015). For the secondary analysis, a thematic analysis was conducted on the veteran focus group data, whereby transcripts were analyzed for themes related to harm reduction. Quotes were extracted and organized into themes that captured the veterans' understanding of harm reduction.

FINDINGS: Various themes emerged from the focus group data with veterans including (a) Regimented Structure, (b) Understanding Both Worlds, (c) Congruent Recovery Journeys, (d) Location: Close Enough to Services, Far Enough from Harm, and (e) Harm Reduction is Housing Stability and Housing Stability is Harm Reduction. These themes represent the interface between the military culture and homeless serving culture. Overall, veterans considered harm reduction as an essential component of housing, as it helped to create stability in their lives.

CONCLUSION: The themes demonstrated that harm reduction may be a part of the solution to veteran homelessness. The findings of this study may inform the way in which nurses, Housing First programs, institutions, and the government address this groups' housing and substance use needs. Additional research is needed to further explore harm reduction among Canadian veterans experiencing homelessness.

Keywords: homelessness, veterans, substance use, harm reduction, Housing First 


\section{CO-AUTHORSHIP STATEMENT}

Olivia Marsella completed this work under the supervision of Dr. Cheryl Forchuk and Dr. Abe Oudshoorn, who will be co-authors on publications produced from this manuscript. 


\section{DEDICATION}

I dedicate this work to my family and friends for their continuous support and encouragement throughout the years. Foremost, I would like to thank my parents, Luigi and Jennifer Marsella, who instilled in me at a very young age the value of hard work and perseverance. Without them, I would not be where I am today and I am forever grateful. I also dedicate this work to the veterans who participated in the Canadian Model for Housing and Support of Veterans Experiencing Homelessness study. It was truly an honor to hear your stories, which have emphasized our obligation as Canadians to support veterans during their critical transition from military service to civilian life. 


\section{ACKNOWLEDGEMENTS}

Firstly, I would like to thank my thesis supervisor, Dr. Cheryl Forchuk, for her continuous guidance and commitment to my growth as a nurse. Thank you for providing me the opportunity to be a Graduate Research Assistant (GRA) at the Mental Health Nursing Research Alliance. This experience as a GRA has completely changed my life and goals as a Registered Nurse. It has instilled in me a compassion for those affected by poverty, mental illness, and homelessness. Furthermore, your dedication and ability to create positive change has made me recognize my own potential as a nurse. I would also like to thank Dr. Abe Oudshoorn for his guidance and expertise on homelessness, mental illness, and harm reduction. I am incredibly thankful for the support that both of you provided to me as I completed this degree.

I also want to acknowledge and thank all my friends for their support and encouragement. To my friend and fellow MScN student, Jenna Richards. I think we can both agree that it would have been tough to get through this degree without each other - thanks for all the good times and laughs! And to my kind and patient boyfriend, Mark Van Leeuwen. Thank you for always being so supportive and understanding throughout these past two years.

Finally, I thank all my family members, especially my parents, Luigi and Jennifer Marsella. Mom and Dad, there is no way I could sufficiently thank you for all that you have done for me throughout my life. I thank God that I was born to such wonderful, loving, and kind parents who care so much about my happiness and success. I owe everything to the both of you and I love you very much. Furthermore, I acknowledge my Mom, who was a Registered Nurse for 35 years. Thank you for inspiring me to pursue nursing and teaching me that it is an honor and privilege to be a nurse.

I thank each one of you for your support. I am forever grateful. 


\section{TABLE OF CONTENTS}

$\begin{array}{ll}\text { Abstract and Keywords } & \text { i }\end{array}$

$\begin{array}{ll}\text { Co-Authorship Statement } & \text { ii }\end{array}$

$\begin{array}{ll}\text { Dedication } & \text { iii }\end{array}$

Acknowledgements

Table of Contents $\quad$ V

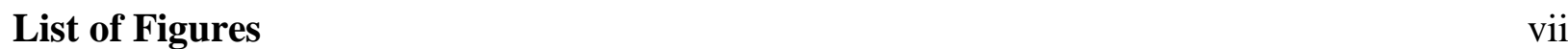

Chapter One

Background and Significance $\quad 1$

Statement of the Problem and Research Questions

Purpose of the Study $\quad 6$

Theoretical Perspective $\quad 6$

$\begin{array}{ll}\text { Methodology } & 7\end{array}$

$\begin{array}{ll}\text { References } & 9\end{array}$

\section{Chapter Two}

Background and Significance 14

Literature Review $\quad 15$

Ethical Approval $\quad 24$

Methodology 24

Study Design 25

Sample and Sampling Method 25

Data Collection $\quad 26$

Data Analysis $\quad 26$

$\begin{array}{ll}\text { Rigor } & 27\end{array}$

Findings 28

Regimented Structure $\quad 29$

Understanding Both Worlds $\quad 32$

Congruent Recovery Journeys $\quad 37$

Location: Close Enough to Services, Far Enough from Harm 38

Harm Reduction is Housing Stability and 40

Housing Stability is Harm Reduction

Discussion and Implications $\quad 42$

Limitations $\quad 50$

Conclusion $\quad 52$

References $\quad 53$ 


\section{Chapter Three}

Implications for Policy

Implications for Housing First Programs

Implications for Nursing Practice

Implications for Nursing Education

Implications for Nursing Research

Conclusion

75

References

Appendix A: Veteran Group Letter of Information 80

Appendix B: Focus Group Invitation $\quad 84$

Appendix C: Semi-structured Interview Guide for Focus Groups 86

$\begin{array}{lr}\text { Curriculum Vitae } & 88\end{array}$ 


\section{LIST OF FIGURES}

Figure

Description

Page

1 The Interface Between Military Culture and Homeless Serving Culture 


\section{CHAPTER I}

\section{Background and Significance}

The incidence of homelessness in Canada has been increasing since the 1980s. This rise in homelessness is largely due to reduced spending on social services and a lack of affordable housing (Gaetz, Dej, Richter, \& Redman, 2016). For decades, the absence of national policies for housing, mental health, and income support has directly contributed to the issue of homelessness. The de-institutionalization of mental health care and limited federal funding for communitybased programs has further led the need for a mental health policy reform in Canada (Sealy \& Whitehead, 2004). This disconnect between income, housing, and mental health care policies has negatively impacted the lives of the many individuals living with mental illness and homelessness (Forchuk et al., 2011).

According to Gaetz et al (2016), approximately 235,000 Canadians will experience homelessness each year. The annual economic burden of homelessness in Canada has been estimated at $\$ 7$ billion, which includes direct and indirect costs, such as shelters and health care services (Gaetz et al., 2016). Furthermore, those suffering from mental health disorders and substance use are disproportionately affected by homelessness (Forchuk, Reiss, Mitchell, Ewen, $\&$ Meier, 2015). For instance, schizophrenia, depression, and illicit drug use are prevalent among the homeless population (Canadian Institute for Health Information, 2007). In Canada, some groups are more at risk for homelessness and mental illness than others; one group that is particularly vulnerable is Canadian Armed Forces (CAF) veterans (Bourque et al., 2015).

According to Segaert and Bauer (2015), little is known regarding the extent of homelessness among CAF veterans in Canada, but there is a concern that is it widespread. A recent report from the Canadian Observatory on Homelessness estimates that approximately 
2,950 veterans are experiencing homelessness. Furthermore, many of these veterans are experiencing more regular or extended times of homelessness, known as episodic and chronic homelessness (Gaetz et al., 2016). Thompson et al (2011) suggest that transitioning from military to civilian life may be challenging for approximately $25 \%$ of veterans. During this critical period, veterans may use alcohol and other drugs to cope with this transition (Ray \& Forchuk, 2011). When problematic, this substance use can contribute to homelessness years after leaving military service (Forchuk \& Richardson, 2015).

There is little data available regarding the current extent of mental health challenges among homeless veterans (Thompson et al., 2014). In 2013, Veterans Affairs Canada administered the Life after Service Survey to veterans of the CAF. Twenty-four percent of Regular Force veterans reported experiencing at least one of either a mood disorder, an anxiety disorder, or posttraumatic stress disorder (PTSD) (Thompsons et al., 2014). Ray and Forchuk (2011) also found that many veterans are struggling with substance use, particularly alcoholism. Often, alcohol use increases during military service and later is used to cope with the transition from military to civilian life (Ray \& Forchuk, 2011). A 2008 to 2009 report by the Department of National Defence revealed that $90 \%$ of CAF Regular Force veterans had consumed alcohol in the previous year (Whitehead \& Hawes, 2010). The lack of stable and affordable housing may be a major risk factor for veteran homelessness (Montgomery, Fargo, Byrne, Kane, \& Culhance, 2013). The Canadian Mental Health Association (CMHA) (2017) suggests that stable housing is key to supporting those with mental health challenges and substance use. A positive living environment can result in increased empowerment, social inclusion, and decreased psychiatric symptoms (CMHA, 2017). Goering et al (2014) also explain that stable housing moves care from the hospital into the community, which results in significant cost savings. However, to 
ensure that housing services meet the unique needs of veterans experiencing homelessness, harm reduction principles can be applied (Pauly, Reist, Belle-Isle, \& Schactman, 2013; Forchuk \& Richardson, 2015). Affordable and safe housing is necessary to facilitate the well-being of veterans experiencing homelessness (Forchuk \& Richardson, 2015).

It is well established that harm reduction effectively addresses the negative impacts of substance use (MacNeil \& Pauly, 2010; Evans, Semogas, Smalley, \& Lohfield, 2015; Pauly et al., 2016). According to Davis, Hawk, Marx, and Hunsaker (2014, p. 156), harm reduction is defined as, "A philosophy of service that encourages positive change regardless of continued risk behaviour." This position branches from the traditional zero-tolerance solution to ceasing substance use (Erickson et al., 2002). Recently, harm reduction practices, such as needle exchange programs, safe injection sites, and managed alcohol programs have been used to address addiction (MacNeil \& Pauly, 2010; Evans et al., 2015; Pauly et al., 2016). Harm reduction is also gaining recognition as an effective principle in addressing the housing needs of individuals experiencing homelessness (Pauly et al., 2013; Goering et al., 2014; Somers, Moniruzzaman, \& Palepu, 2016). Since substance use and homelessness are often co-occurring (Torchalla, Strehlau, Li, \& Krauz, 2011), harm reduction principles may lead to improved housing stability.

In Canada, Housing First has been used to facilitate access to permanent housing for individuals experiencing homelessness. Housing First includes the philosophy of harm reduction, whereby individuals are not required to abstain from alcohol and other drugs or undergo treatment before being housed (Gaetz, Scott, \& Gulliver, 2013). Rather, housing is viewed as a human right. Central to Housing First is the utilization of a client-centred approach to securing housing. Rather than subscribing solely to agency-driven goals, the unique needs of individuals 
are incorporated into services (Young \& Manion, 2017). Research suggests that implementing the Housing First model can result in better long-term outcomes (Montgomery, Hill, Kane, \& Culhane, 2013; Hwang \& Burns, 2014).

Evidence has shown that client-centred approaches to achieving stable housing, such as harm reduction, empower individuals to reduce the harm of their substance use (WaegmakersSchiff \& Turner, 2014; McIntyre, 2009). Despite research demonstrating the potential benefits of harm reduction approaches, this method continues to face criticism, as well as elicit discomfort, from the public (Young \& Manion, 2017). Critics of harm reduction argue that this method may encourage people to engage in drug misuse. This opposition may be the result of society's deeply-rooted belief that addiction is a personal and intolerable choice (Cortina, 2013). According to Corrigan, Kuwabara, and O’Shaughnessy (2009), people who use illicit drugs are often described as dangerous and blameworthy. Given the conflicting opinions and attitudes towards harm reduction, it is important to explore how CAF veterans experiencing homelessness understand this approach.

The high incidence of chronic and episodic homelessness among veterans (Gaetz et al., 2016) illustrate that housing stability has not been fully achieved for this unique group. Without adequate resources, such as housing, to support these individuals in the community, the number of veterans experiencing homelessness is likely to rise. However, harm reduction may be particularly effective in creating housing stability for this group (Bourque et al., 2015; Forchuk \& Richardson, 2015). This research will provide further insight into the use of harm reduction among veterans experiencing homelessness. By exploring harm reduction among this group, evidence may be provided to support or refute its incorporation into future housing models. Understanding veterans' perceptions of and experiences with harm reduction may enable the 
government, institutions, and health care professionals to adequately address this population's specific health and social needs. Additional research may also help to close the knowledge gap in Canada regarding the state of veteran homelessness.

\section{Statement of the Problem and Research Questions}

According to a report by the Canadian Observatory on Homelessness and the Canadian Alliance to End Homelessness, approximately 235,000 or more Canadians will experience homelessness each year (Gaetz et al., 2016). Current statistics suggest that there are roughly 2,950 homeless veterans in Canada and they represent about $2.2 \%$ of the population accessing emergency homeless shelters, which is only one form of homelessness (Gaetz et al., 2016). In a study by Ray and Forchuk (2011), veterans expressed their desire for affordable housing services that are designed specifically to help address their addiction and mental health challenges. In a further study, Forchuk and Richardson (2015) found that one of the key principles for addressing homelessness among Canadian veterans was harm reduction. Harm reduction and Housing First have begun to show effectiveness as solutions to homelessness among veterans (Bourque et al., 2015; Forchuk \& Richardson, 2015). There is a nation-wide effort to develop innovative solutions to address homelessness (Gaetz et al., 2016). Given the importance of harm reduction as a principle to address veteran homelessness, one avenue that can be explored is to understand how veterans experience and describe harm reduction. Throughout this study, the following research questions were addressed:

1. What are the experiences with harm reduction for Canadian veterans who have experienced homelessness?

2. What does harm reduction mean for Canadian veterans who have experienced homelessness? 


\section{Purpose of the Study}

The purpose of this study is to explore how homeless veterans experience and perceive harm reduction approaches as a component of stable housing. This study was a secondary qualitative analysis of data collected for the Canadian Model for Housing and Support of Veterans Experiencing Homelessness, a two-year project that evaluated a housing model and individualized programming for veterans $(N=78)$ experiencing or at risk for homelessness (Forchuk \& Richardson, 2015). The purpose of the primary study was to further explore homelessness among veterans and to test the application of a veteran-specific housing model in Toronto, Calgary, London, and Victoria. The qualitative data for this study was collected primarily through focus groups conducted in three cycles at each of the four program sites (Forchuk \& Richardson, 2015). This secondary analysis examined this data for emerging themes related to harm reduction. Exploring homeless veterans' understanding of and experiences with harm reduction may be helpful in identifying their unique health and housing needs.

\section{Theoretical Perspective}

This study was conducted within an interpretive lens, therefore the aim was not to test theories and hypotheses to produce empirical evidence (Morse, 2003; Achinstein, 2010). Rather, the focus of this lens is to understand situations, individuals, cultures, and populations for the purpose of theory generation (Apel, 2011). This method of inquiry supports exploring how people interpret, perceive, or make sense of their surroundings and experiences (Morse \& Field, 1996). The purpose of this study is to explore how veterans experiencing homelessness understand and experience harm reduction as it relates to housing. Therefore, a particular a priori theory was not used during data analysis to prevent threats to the research design (Morse, 2003). 
However, the framework of harm reduction was considered after the data analysis phase and is reported in the discussion found in the manuscript.

\section{Methodology}

A qualitative secondary analysis was used to examine data from the Canadian Model for Housing and Support of Veterans Experiencing Homelessness study (Forchuk \& Richardson, 2015). According to Heaton (2004b), secondary analysis involves analyzing both pre-existing quantitative and qualitative data. Forms of qualitative data frequently analyzed through secondary analysis include field notes, observational records, and tape recordings and transcripts of interviews and focus groups. The re-use of qualitative data within social research has been used to inform and publish secondary studies (Heaton, 2004b).

There are various purposes of a qualitative secondary analysis within social research. This type of analysis allows researchers to investigate new research questions, verify or refine existing research, and synthesize knowledge from existing studies (Heaton, 2004a). For the purposes of this study, qualitative secondary analysis was used to further explore the concept of harm reduction using data from the primary study (Forchuk \& Richardson, 2015).

There are five varieties of qualitative secondary analysis including supra analysis, supplementary analysis, re-analysis, amplified analysis, and assorted analysis (Heaton, 2004a). In this study, a supplementary analysis was used to examine pre-existing qualitative data relating to harm reduction. This type of analysis is defined as, "A more in-depth investigation of an emergent issue or aspect of the study which was not considered or fully addressed in the primary study" (Heaton, 2004a, p. 38). Forchuk and Richardson's (2015) study aimed to explore homelessness among veterans and to assess the implementation of a housing model for this population. Data analysis from focus groups with veterans revealed several themes relating to 
harm reduction, particularly that it was one of the principles that was needed to address veteran homelessness. Supplementary secondary analysis was used to explore these themes further to uncover how veterans understand and experience harm reduction. 


\section{References}

Achinstein, P. (2010). Evidence, explanation, and realism. Oxford: Oxford University Press.

Apel, J. (2011). On the meaning and the epistemological relevance of the notion of a scientific phenomenon. Synthese, 182(1), 23-38. doi: 10.1007/s11229-009-9620-7

Bourque, J., VanTil, L., Gibbons, C., LeBlanc, S., Landry, A., LeBlanc, J.,...More, F. (2015). Impact of a housing first intervention on homeless veterans with mental illness: a Canadian multisite randomized controlled trial. Journal of Military, Veteran, and Family Health, 1(2). doi: 10.3138/jmvfh.2985

Canadian Institute for Health Information. (2007). Improving the health of Canadians: Mental health and homelessness. Ottawa, ON: Author. Retrieved from https://secure.cihi.ca/free _products/mental_health_report_aug22_2007_e.pdf

Canadian Mental Health Association. (2017). Homelessness. Retrieved from http://www.cmha.ca /public-policy/subject/homelessness/

Corrigan, P. W., Kuwabara, S. A., \& O’Shaughnessy, J. (2009). The public stigma of mental illness and drug addiction: Findings from a stratified random sample. Journal of Social Work, 9(2), 139-147. doi: 10.1177/1468017308101818

Cortina, S. C. (2013). Stigmatizing harm reduction through language. Journal of Addictions Nursing, 24(2), 102-107. doi: 10.1097/JAN.0b013e3182929466

Davis, D., Hawk, M., Marx, J., \& Hunsaker, A. (2014). Mechanisms of adherence in a harm reduction housing program. Journal of Social Work Practice in the Addictions, 14, 155174. doi: 1 0.1080/1533256X.2014.902702

Erickson, P., Butters, J., Walkom K., Butterill, D., Caverson, R., Fischer, B., ... Tupker, E. (2002). CAMH and harm reduction: A background paper on its meaning and application 
for substance use issues. Retrieved from http://www.camh.ca/en/hospital/about_camh/ influencing_public_policy/public_policy_submissions/harm_reduction/Pages/harmreduct ionbackground.aspx

Evans, J., Semogas, D., Smalley, J. G., \& Lohfeld, L. (2015). “This place has given me a reason to care": Understanding 'managed alcohol programs' as enabling places in Canada. Health \& Place, 33, 118-124. doi: 10.1016/j.healthplace.2015.02.011

Forchuk, C., Reiss, J. P., Mitchell, B., Ewen, S., \& Meier, A. (2015). Homelessness and housing crises among individuals accessing services within a Canadian emergency department. Journal of Psychiatric and Mental Health Nursing, 22, 354-359. doi: 10.1111/jpm.12212

Forchuk, C., \& Richardson, J. (2015). A Canadian model for housing and support of veterans experiencing homelessness: Housing first practice manual. London, ON: City of London. Retrieved from http://www.homelessprevention.ca

Forchuk, C., Schofield, R., Joplin, L., Csiernik, R., Gorlick, C., \& Turner, K. (2011). Housing, income support, and mental health: Points of disconnection. In C. Forchuk, Csiernik, R., \& Jensen, E. (Eds), Homelessness, Housing, and Mental Health: Finding Truths Creating Change (35-49). Toronto, ON: Canadian Scholars’ Press Inc.

Gaetz, S., Dej, E., Richter, T., \& Redman, M. (2016). The state of homelessness in Canada 2016. Toronto, ON: Canadian Observatory on Homelessness Press. Retrieved from http://homelesshub.ca/sites/default/files/SOHC16_final_20Oct2016.pdf

Gaetz, S., Scott, A., \& Gulliver, T. (2013). Housing first in Canada: Supporting communities to end homelessness. Retrieved from http://www.homelesshub.ca/sites/default/files/HousingFirstInCanada_0.pdf

Goering, P., Veldhuizen, S., Watson, A., Adair, C., Kopp, B., Latimer, E., ... Aubry, T. (2014). 
National at Home/Chez Soi Final Project. Calgary, AB: Mental Health Commission of Canada. Retrieved from http://www.mentalhealthcommission.ca/English/system/files/ private/document/mhcc_at_home_report_national_cross-site_eng_2.pdf.

Heaton, J. (2004a). Chapter 3: Types of qualitative secondary analysis. In Heaton, J. (Eds), Reworking Qualitative Data (35-52). London, Thousand Oaks, New Delhi: Sage Publications Inc.

Heaton, J. (2004b). Chapter 1: What is secondary analysis? In Heaton, J. (Eds), Reworking Qualitative Data (1-16). London, Thousand Oaks, New Delhi: Sage Publications Inc.

Hwang, S. W., \& Burns, T. (2014). Health interventions for people who are homeless. Lancet, 384(9953), 1541-7. doi: 10.1016/S0140-6736(14)61133-8.

MacNeil, J., \& Pauly, B. M. (2010). Needle exchange as a safe haven in an unsafe world. Drug \& Alcohol Review, 30(1), 26-32. doi: 10.1111/j.1465-3362.2010.00188.x

McIntyre, S. (2009) Wet housing: an accommodation option for people who have experienced chronic homelessness and long-term alcohol dependence. Retrieved from, http://www.scribd.com/doc/49885009/Wet-House- Stephanie-McIntyre-ChurchillReport-2009\#scribd.

Montgomery, A. E., Fargo, J. D., Byrne, T. H., Kane, V., \& Culhane, D. P. (2013). Universal screening for homelessness and risk for homelessness in the veterans health administration. American Journal of Public Health, 103(2), S210-S211. doi:10.2105/AJPH.2013.301398

Montgomery, A. E., Hill, L. L., Kane, V., \& Culhane, D. P. (2013). Housing chronically homeless veterans: Evaluating the efficacy of a housing first approach to HUD-VASH. Journal of Community Psychology, 41(4), 505-514. doi: 10.1002/jcop.21554 
Morse, J. M. (2003). A review committee's guide to evaluating qualitative proposals. Qualitative Health Research, 13(6), 833-851. doi: 10.1177/1049732303255367

Morse, J. M., \& Field, P. A. (1996). The purpose of qualitative research. In J. M. Morse \& P. A. Field (Eds.), Nursing Research (pp. 1-17). Boston, MA: Springer.

Pauly, B., Gray, E., Perkin, K., Chow, C., Vallace, K., Krysowaty, B., \& Stockwell, T. (2016). Finding safety: A pilot study of managed alcohol programs participants' perceptions of housing and quality of life. Harm Reduction Journal, 13(15), 1-11. doi: 10.1186/s12954016-0102-5

Pauly, B., Reist, D., Belle-Isle, L., \& Schactman, C. (2013). Housing and harm reduction: What is the role of harm reduction in addressing homelessness? International Journal of Drug Policy, 24, 284-290. doi: 10.1016/j.drugpo.2013.03.008

Ray, S. L., \& Forchuk, C. (2011). Experience of homelessness among Canadian Forces and allied forces Veterans (Research Report submitted to HRSDC Canada). Retrieved from http://www. homelesshub.ca/sites/default/ les/Homelesss\%20Vets\%20Article.pdf

Sealy, P., \& Whitehead, P. C. (2004). Forty years of deinstitutionalization of psychiatric services in Canada: An empirical assessment. The Canadian Journal of Psychiatry,49(4), 249257. Retrieved from http://journals.sagepub.com/home/cpa

Segaert, A., \& Bauer, A. (2015). The extent and nature of veteran homelessness in Canada. Retrieved from https://www.canada.ca/en/employment-socialdevelopment/programs/communities/homelessness/publications-bulletins/veteransreport.html

Somers, J. M., Moniruzzaman, A., \& Palepu, A. (2015). Changes in daily substance use among people experiencing homelessness and mental illness: 24-month outcomes following 
randomization to Housing First or usual care. Addiction, 110, 1605-1614. doi:

10.1111/add.13011

Thompson, J. M., MacLean, M. B., Van Til, L., Sudom, K., Sweet, J., Poirier, A., ... Pedlar, D. (2011). Survey on transition to civilian life: Report on regular force veterans.

Charlottetown, P.E.I.: Research Directorate, Veterans Affairs Canada; Ottawa.

Thompson, J., Van Til., L., Poirier, A., Sweet, J., McKinnon, K., \& Pedlar, D. (2014). Health

and well-being of Canadian Armed Forces veterans: Findings from the 2013 Life After

Service survey. Charlottetown: Research Directorate, Veterans Affairs Canada; Ottawa.

Retrieved from http://publications.gc.ca/collections/collection_2016/acc-vac/V32-2522014-eng.pdf

Torchalla, I., Strehlau, V., Li., K., \& Krauz, M. (2011). Substance use and predictors of substance dependence in homeless women. Drug and Alcohol Dependence, 18(2-3), 173179. doi: 10.1016/j.drugalcdep.2011.03.016.

Waegemakers Schiff, J. W., \& Turner, A. Housing First in rural Canada: rural homelessness and Housing First feasibility across 22 Canadian communities. Retrieved from http://www.homelesshub.ca/sites/default/files/Rural_Homelessness_in_Canada_2014.pdf

Whitehead, J., \& Hawes, R. A. (2010). Canadian Forces health and lifestyle information survey 2008/09 Regular Force report. Ottawa, Ontario, Canada: Canadian Forces Health Services Group, Department of National Defence.

Young, M. G., \& Manion, K. (2017). Harm reduction through housing first: An assessment of the emergency warming center in Inuvik, Canada. Harm Reduction Journal, 14(8), 1-11. doi: 1 0.1186/s12954-016-0128-8 


\section{CHAPTER II}

\section{MANUSCRIPT}

\section{Background and Significance}

It is well-established that mental illness is associated with poverty and homelessness (Hwang, 2001; Public Health Agency of Canada, 2006; Canadian Institute for Health Information [CIHI], 2007). However, the dynamics of this relationship are incredibly complex. For decades, the lack of national policies for housing, income support, and mental health has contributed to the growing rate of homelessness in Canada (Draine, Salzer, Culhane, \& Hadley, 2002; Forchuk et al., 2007). Furthermore, the deinstitutionalization of mental health care has directly resulted in housing instability for many vulnerable groups (Forchuk et al., 2011). Individuals experiencing substance use disorders are disproportionally affected by homelessness (Forchuk, Reiss, Mitchell, Ewen, \& Meier, 2015). Substance use, particularly alcohol use, is wide-spread among people experiencing homelessness (Podymow, Turnbull, Coyle, Yetisir, \& Wells, 2006; CIHI, 2007). In the last decade, the homeless population has become increasingly diverse, with more youths, families, and women experiencing homelessness. Therefore, the key to preventing homelessness may be to address the needs of unique groups of people experiencing homelessness (Gaetz, Dej, Richter, \& Redman, 2016). A group that is also gaining recognition as high-risk for homelessness is Canadian Armed Forces (CAF) veterans (Gaetz et al., 2016; Ray \& Forchuk, 2011).

In Canada, CAF veterans are at an increased risk for homelessness, yet there is little evidence to demonstrate the extent of homelessness among this population (Ray \& Forchuk, 2011; Bourque et al., 2014). A recent report suggests that there are approximately $2,950 \mathrm{CAF}$ veterans are homeless across the country (Gaetz et al., 2016). Some veterans experience 
substance use disorders, particularly alcoholism, many years after exiting military service that has been linked to their loss of housing and subsequent homelessness (Whitehead \& Hawes, 2010; Ray \& Forchuk, 2011). Harm reduction is a strategy to address substance use (Thomas, 2005) and was identified by Forchuk and Richardson (2015) as a key principle to preventing veteran homelessness.

Harm reduction is a recovery-oriented, evidence-based approach that aims to reduce the harms of substance use without requiring individuals to abstain from substances (Thomas, 2005). Evidence has shown that harm reduction reduces the negative consequences associated with substance use (MacNeil \& Pauly, 2010; Evans, Semogas, Smalley, \& Lohfield, 2015; Pauly et al., 2016). Housing First includes the principle of harm reduction and facilitates, as quickly as possible, access to stable, permanent, affordable, and supported housing of choice. Unlike traditional zero-tolerance housing models, this strategy does not require individuals to abstain from substance use to receive housing (Gaetz, Scott, \& Gulliver, 2013). Harm reduction and Housing First may be key to addressing the high incidences of homelessness among CAF veterans (Forchuk \& Richardson, 2015). Previous studies have shown that veterans desire stable and affordable housing that takes into consideration their unique mental health and addiction needs (Ray \& Forchuk, 2011; Forchuk \& Richardson, 2015). This study will further explore how homeless veterans experience and perceive harm reduction as a component of stable housing. Uncovering the meaning of harm reduction for veterans experiencing homelessness may influence how agencies, institutions, and the government address this group's housing needs.

\section{Literature Review}

To understand both the extent of homelessness among veterans and the current use of harm reduction to address homelessness in Canada, a literature review was performed by 
searching the Cumulative Index to Nursing and Allied Health Literature, Scopus, and PubMed online databases. However, only abstracts and peer-reviewed articles written in English and published between 2012 and 2017 were included in this review, as Housing First and harm reduction in services for veterans experiencing homelessness are a relatively new phenomenon. This study is concerned specifically with the experiences of Canadian veterans, so the focus of this review will be on Canadian literature with some comparisons to other nations.

Research from other countries, at times, has limited applicability as both the experience of being in the military and post-service supports and programming differ significantly (Ray \& Forchuk, 2011). While most research on veteran homelessness focuses on the American context, the Canadian context is significantly different than that of the United States (U.S.) (Ray \& Forchuk, 2011; Segaert \& Bauer, 2015). In particular, U.S. literature tends to highlight Post Traumatic Stress Disorder with a rapid entry into homelessness after leaving the Armed Forces (Carlson, Garvert, Macia, Ruzek, \& Burling, 2013; Dinnen, Kane, \& Cook, 2014; U.S. Department of Housing and Urban Development, 2011). Conversely, Canadian veterans have identified substance use, primarily alcoholism, as the main concern and reported homelessness more than a decade after leaving the armed services. They describe reconnecting with their military experience as an important part of their recovery, which would be inappropriate for someone freshly experiencing PTSD (Ray \& Forchuk, 2011; Forchuk \& Richardson, 2015).

Research in the United Kingdom (U.K.) has found that substance use during service and a difficult transition can contribute to veteran homelessness (Johnsen, Jones, \& Rugg, 2008; Dandeker, Thomas, Dolan, Chapman, \& Ross, 2005). However, the primary cause of veteran homelessness has been cited as relationship breakdown, such as divorce, which was not found in the Canadian literature (Johnsen et al., 2008). With these marked differences, findings regarding 
such issues as the extent and nature of veteran homelessness in other countries, such as the U.S. and U.K., may not be transferrable (Segaert \& Bauer, 2015). This review was intended to explore the current state of homelessness among veterans and the use of harm reduction to facilitate stable housing in Canada. However, the findings of this study will be compared to literature from other countries in the discussion of this manuscript.

Multiple search terms were used during this review, including "Veterans", "Homeless", “Homelessness”, “Substance Use, “Housing”, "Housing First”, and "Harm Reduction”.

Relevancy was determined by reading the abstracts and key words of each article that was produced. The reference lists of the articles were also reviewed for additional relevant literature. In total, this review identified eleven Canadian articles relating to the purpose of this study. The literature has been organized into two categories, Canadian Veterans Experiencing Homelessness and Harm Reduction and Housing First to Facilitate Housing.

\section{Canadian Veterans Experiencing Homelessness}

Four articles were found which examined veteran homelessness in Canada. This relatively small number is congruent with the general lack of research in Canada on veterans. In an interpretive phenomenological study by Ray and Forchuk (2011), 54 interviews with veterans were conducted to understand their lived experiences and to identify the causes of homelessness within this group. The researchers found that many veterans experienced alcohol and drug addiction as well as mental health challenges (Ray \& Forchuk, 2011). The combination of these problems resulted in a "downward spiral” into homelessness many years after exiting the military. Often, veterans used substances to cope with the difficult transition from the military to civilian life. They expressed the need for affordable housing specifically for veterans. Without adequate housing, veterans must access shelters, which perpetuates the cycle of homelessness 
(Ray \& Forchuk, 2011). Overall, this study highlighted the unique issues that homeless Canadian veterans experience. However, the authors suggest that further research is needed to inform future housing services that are specific to veterans’ needs (Ray \& Forchuk, 2011).

Bourque et al (2014) conducted a study to determine the correlation of veteran status with housing, mental health, and service use. Data was retrieved from the At Home/Chez Soi study, which examined the implementation of a Housing First model in various Canadian cities (Bourque et al., 2014). Of the 2298 participants enrolled in this study, 99 (4.3\%) identified as veterans. The researchers matched 297 demographically similar non-veteran participants with three veterans based on study site, age, and sex. The study revealed that both groups were quite similar and generally experienced poor health. The incidence of various disorders, such as PTSD, were not significantly different between the two groups. The researchers hypothesized that homelessness may be equally detrimental to veterans and non-veterans alike (Bourque et al., 2014). A major limitation of this study was the use of data from the At Home/Chez Soi study, since it did not specifically aim to study veterans' experiences. Furthermore, the similarity of findings between non-veterans and veterans could have been a result of the matching process the authors used within the sample. Since the sample was matched based on age, sex, and study site, any differences in these characteristics between the groups would have gone undetected, which could have significantly altered the results of the study.

Employment and Social Development Canada examined the extent and nature of veteran homelessness in Canada (Segaert \& Bauer, 2015). Data from the Homeless Individuals and Families Information System (HIFIS) was used to compare veterans $(N=338)$ with non-veterans $(N=12,017)$. The authors found that veterans were typically older than those who did not indicate military service. Episodic homelessness, defined as three or more instances of homelessness 
annually, was experienced by $15.7 \%$ of veterans and $8.6 \%$ of non-veterans. This high rate of episodic homelessness among veterans may suggest that they are "living rough" on the streets (Sagaert \& Bauer, 2015). Since this study analyzed shelter use data, it may not accurately reflect the true number of veterans experiencing homelessness in the country. Furthermore, data relating to veteran-status was often missing or unknown in the HIFIS database. Despite these limitations, this study captured important characteristics about veteran homelessness.

This secondary analysis examined data from The Canadian Model for Housing and Support of Veterans Experiencing Homelessness (Forchuk \& Richardson, 2015), which has previously been described. The primary study revealed that veterans often experience chronic homelessness and physical and mental health issues years after leaving military service. For many veterans, a prolonged period of destabilization eventually resulted in homelessness (Forchuk \& Richardson, 2015). Veterans often expressed a strong desire to re-connect with the military culture and to access structured housing that incorporates harm reduction. Data analysis showed that the housing model resulted in significant cost savings and reduced hospital, emergency room, and drop-in-center use (Forchuk \& Richardson, 2015). Furthermore, collaboration with local services and organizations facilitated timely access to permanent housing for veterans. Overall, the housing model improved access to the resources the veterans needed to address their housing, health, and social needs. Only one veteran across all four sites returned to homelessness (Forchuk and Richardson, 2015).

Overall, the literature suggests that homelessness among Canadian veterans is of continuing concern. When veterans exit the military, they often experience mental health issues and problematic substance use many years later (Forchuk \& Richardson, 2015). Without the appropriate supports to deal with these challenges, veterans are at imminent risk for 
homelessness (Ray \& Forchuk, 2011). The lack of stable and affordable housing is a major contributing factor to veteran homelessness. Veterans have suggested that housing services designed specifically for their unique needs are needed to end the cycle of homelessness (Ray \& Forchuk, 2011). Providing permanent and long-term stable housing that incorporates harm reduction is necessary to support veterans who are homeless (Forchuk \& Richardson, 2015). Given that more than 2,950 veterans may be homeless in Canada (Gaetz et al., 2016), further research involving this population is needed.

\section{Harm Reduction and Housing First to Facilitate Housing}

Studies have assessed the effectiveness of harm reduction and Housing First in addressing homelessness in Canada. However, during this literature review, no articles were found that aimed to explore harm reduction among an exclusively veteran sample. One article was identified which examined the impact of Housing First on veterans experiencing homelessness and mental health challenges (Bourque et al., 2015). In total, eight articles were identified which explored the use of harm reduction or Housing First to facilitate housing stability for people experiencing homelessness, including veterans, in Canada.

Pauly, Reist, Belle-Isle, and Schactman (2013) explored Housing First as a method of integrating harm reduction into housing services in Victoria, British Columbia. As part of the Greater Victoria Coalition to End Homelessness, the authors developed a policy framework to provide a systems-level method of incorporating harm reduction into housing initiatives. It is comprised of four key dimensions including, "(1) developing policies of social inclusion; (2) ensuring an adequate supply of housing; (3) providing on demand harm reduction services; and (4) systematic and organizational structure" (Pauly et al., 2013, p. 286). Each of these four dimensions interact to facilitate access to stable housing that is based on the harm reduction 
philosophy. The authors suggested that harm reduction may address the barriers that people experience when obtaining housing. They also emphasized the need for further research on harm reduction to demonstrate its effectiveness in creating housing stability (Pauly et al., 2013).

The Mental Health Commission of Canada examined the effectiveness of Housing First among individuals experiencing mental illness and homelessness (Goering et al., 2014). The project, referred to as At Home/Chez Soi, was implemented in Vancouver, Winnipeg, Toronto, Montreal, and Moncton. Existing housing models in these cities were compared to Housing First to determine which methods were most effective. In total, 2148 individuals were recruited from the shelters or streets and randomized to receive either Housing First or the existing housing approach (Goering et al., 2014). This study showed that participants who received Housing First retained stable housing for much longer than those who received the usual housing practices. In the final six months of the study, $68 \%$ of the Housing First groups were housed stably compared to $31 \%$ in the comparison group. Housing First also resulted in increased quality of life and improved social functioning. Goering et al (2014) suggested that Housing First programs may need to be tailored to the unique needs of homeless subgroups, such as veterans. Overall, this study supported the continued implementation of Housing First programs in Canada.

The Vancouver At Home study was part of the multi-site At Home/Chez Soi project (Goering et al., 2014; Somers, Moniruzzaman, \& Palepu, 2015). As part of this study, Somers et al (2015) conducted two randomized control trials to compare daily substance use (DSU) among those receiving Housing First or existing housing services. Participants were randomized to receive either Housing First interventions with intensive case management (ICM) or treatment as usual (TAU). DSU was assessed at 12 and 24 months using data from the Maudsley Addiction Profile. Analysis of data showed no difference in DSU between the ICM and TAU groups 
(Somers et al., 2015). Although there were no differences between the groups, the experimental design was not able to identify the responsible mechanisms. Furthermore, 24 months may not have been a long enough period to detect changes in DSU between the groups (Somers et al., 2015). Nevertheless, the researchers recommended that Housing First be further adapted to support those experiencing problematic substance use (Somers et al., 2015).

Data from the At Home/Chez Soi study (Goering et al., 2014) was also analyzed by Bourque et al (2015) to examine Housing First among 98 veterans experiencing homelessness and mental health problems. The aim of this study was to identify the impact of Housing First on veterans' housing stability, social functioning, and quality of life. The veterans were randomized to either a control group ( $n=41)$ or intervention group $(n=57)$, which received the Housing First intervention and the associated supports. Data analysis revealed that Housing First resulted in several positive outcomes among the veterans who received the intervention, including improved quality of life, greater social functioning, and increased housing stability. Despite the small veteran sample, this study demonstrated that veterans experiencing homelessness and mental health challenges may benefit from a Housing First intervention (Bourque et al., 2015).

Young and Manion (2017) examined the effectiveness of an Emergency Warming Shelter (EWC) in Inuvik, Northwest Territories. This low-barrier shelter is based on harm reduction principles and provides a safe place for people experiencing homelessness to sleep and eat (Young \& Manion, 2017). Although substance use is prohibited in the shelter, those under the influence are permitted to stay overnight. While providing protection from the harsh weather conditions, the EWC also facilitates access to supports for its residents. Interviews and focus groups with 20 residents revealed that the EWC was a safe and warm environment for those experiencing homelessness and concurrent disorders. However, the shelter did not have a 
significant impact on residents' substance use (Young \& Manion, 2017). There were various limitations of this study, including the use of a small sample size. Furthermore, the EWC offers little in terms of harm reduction, as substance use is not allowed on-site; it simply allows a lower barrier around inebriation. Secondly, although it might provide some of the prevention component of Housing First, the service did not provide permanent housing. Despite this limitation, this study demonstrated that having a safe place to stay is essential for individuals experiencing homelessness and substance use (Young \& Manion, 2017).

Studies have also assessed the effectiveness of managed alcohol programs (MAPs) in facilitating access to stable housing for individuals with an alcohol addiction (Evans et al., 2015; Pauly et al., 2016; Vallance et al., 2016). Managed alcohol programs are defined as an, "Approach to re-housing homeless people with alcohol use disorders that couples supportive housing with on-site, supervised access to beverage alcohol" (Evans et al., 2015, p. 118). Evans et al (2015) explored the experiences of 10 males with a MAP in Ontario, Canada. In-depth interviews and focus groups revealed that MAPs were enabling places that created a sense of community as well as promoted self-management (Evans et al., 2015). However, these findings emerged from a single case study with an exclusively male sample, so the results should be treated with caution (Evans et al., 2015). An additional mixed methods study by Pauly et al (2016) evaluated a MAP in Thunder Bay, Ontario. Residents of the MAP reported that it was a safer alternative to shelters, jails, hospitals, and the streets. The MAP also reduced the harms associated with alcohol use and facilitated respect and trust among residents (Pauly et al., 2016). Vallance et al (2016) also assessed the effect of this MAP on patterns of alcohol consumption among 18 participants. The study found that the MAP resulted in fewer hospital admissions, detox episodes, and police encounters. Furthermore, it reduced some alcohol-related harms, such 
as non-alcohol beverage consumption. However, the small sample size and lack of randomization may have limited the results of this study (Vallance et al., 2016).

These studies have shown that harm reduction and Housing First may be an effective part of the solution to homelessness, including veteran homelessness (Pauly et al., 2013; Goering et al., 2014; Bourque et al., 2015). Housing First has resulted in increased housing retention, improved quality of life, and reduced substance-related harms (Goering et al., 2014; Bourque et al., 2015; Vallance et al., 2016). Other housing services that incorporate harm reduction, such as MAPs, have been shown to create healing environments for those struggling with addiction (Evans et al., 2015; Pauly et al., 2016; Vallance et al., 2016). However, no literature was found that explored harm reduction among Canadian veterans experiencing homelessness. Further research is needed to understand how this population experiences and perceives harm reduction.

\section{Ethical Approval}

The University of Western Ontario’s research ethics board for Health Sciences Research Involving Human Subjects granted approval for the primary study. During the consent process, participants approved of having their data used for secondary analyses. The participants were given a letter of information (see Appendix A) which outlined the purpose of the study and their rights as research participants. Electronic data files were stored on a password-protected computer that was accessible by only the primary researcher and research staff. Hard copies of data files were stored in a locked filing cabinet. To ensure confidentiality, all participants were assigned an identification code.

\section{Methodology}

A qualitative secondary analysis was used to re-analyze focus group data from the Canadian Model for Housing and Support of Veterans Experiencing Homelessness study 
(Forchuk \& Richardson, 2015). According to Heaton (2004d; 2004c), a secondary analysis examines pre-existing qualitative or quantitative data to investigate new research questions or confirm existing research. This study used a supplementary secondary analysis to re-analyze veteran focus group data from the primary study. This variety of secondary analysis investigates an issue or situation that was not considered or fully examined in the original research (Heaton, 2004c). In the primary study, several themes related to harm reduction emerged from the focus groups with veterans. In this study, these themes were examined more deeply to reveal how veterans who have experienced homelessness experience and understand harm reduction.

\section{Study Design}

To conduct this supplementary secondary analysis, focus group data from veterans in The Canadian Model for Housing and Support of Veterans Experiencing Homelessness was analyzed. This two-year study evaluated a housing model and individualized programming for veterans experiencing or at risk for homelessness in four Canadian cities including London, Victoria, Toronto, and Calgary (Forchuk \& Richardson, 2015). The qualitative component of this study involved focus group interviews with veterans, housing staff, and other key stakeholders who referred to the program or received referrals from the program. Focus groups occurred at three time-points at all four sites. The purpose of these encounters was to understand veterans' experiences with the housing model and to identify recommendations for its future implementation. This supplementary analysis examined data from only the veteran focus groups with a focus on the experiences of harm reduction.

\section{Sample and Sampling Method}

In the primary study, veterans residing at each of the four housing sites were surveyed and invited to the focus groups (see Appendix B). Veterans were eligible to enroll in the primary 
study and to participate in the focus groups if they (a) were Canadian veterans enrolled in one of the four housing programs; (b) had a history or risk of homelessness; (c) capable of giving informed consent; and (d) able to speak English. Homelessness was defined as using a shelter system or living on the streets or in abandoned buildings, tents, under bridges, or in cars. In total, 78 veterans participated in the study and received the housing and related programming intervention. All the veterans were given the choice to participate in the three focus groups. However, accommodations were made if they were unable to attend at the planned focus group time. Attendees of focus groups included those who were currently involved in the program as well as former tenants who received housing services from the four programs. Across all sites, 24 veterans attended both the 2012 and 2013 focus groups. A total of 39 veterans attended the final focus groups in 2014 (Forchuk \& Richardson, 2015).

\section{Data Collection}

Data for the primary study was collected from veterans, service providers, and stakeholders from 2012 to 2014. Quantitative demographic data was collected via structured interviews with veterans at baseline, 3, 9, and 15 months (Forchuk \& Richardson, 2015). Qualitative data was collected through focus groups and interviews conducted in three cycles. All participants were required to read and sign a consent form. These encounters were audio recorded and usually lasted 20 minutes to two hours. These recordings were then transcribed verbatim by trained research assistants. Participants were given a $\$ 20$ honorarium for their participation. Data from thirteen focus groups and one individual interview were analyzed.

\section{Data Analysis}

There are various methods of analyzing qualitative data for a secondary analysis. In this supplementary analysis, the process of re-coding (Heaton, 2004c) was used to analyze data from 
the focus groups conducted with veterans. Prior to analysis, audio recordings of the focus groups were listened to, to ensure the accuracy of the transcripts (Szabo \& Strang, 1997). Listening to these audio recordings also provided an in-depth understanding of the veterans' experiences. As Weber (1986) explains, transcribing verbatim often eliminates significant characteristics of language and communication, such as tone of voice and emphasis. Listening to the veterans describe their experiences added a deeper dimension to this secondary analysis.

Transcripts from the focus groups and individual interview were examined for themes related to harm reduction. Specific quotes from the transcripts were coded and organized into the respective themes (Heaton, 2004b). The transcripts were read repeatedly until no new themes related to harm reduction were identified. The findings were then presented to an advisory committee member and the principle investigator of the primary study to confirm or modify the themes. The purpose of this analysis was to provide further insight into how veterans experiencing homelessness describe and experience harm reduction. By re-coding the primary focus group data, themes related to harm reduction could be explored further.

\section{Rigor}

Secondary analyses must achieve methodological rigour to contribute to the development of new knowledge (Szabo \& Strang, 1997). Heaton (2004b) outlines various techniques secondary researchers can use to ensure the rigor of data, including triangulation and audit trails. Triangulation may be accomplished by presenting the emerging themes or categories to the original researcher for validation (Szabo \& Strang, 1997). During this secondary analysis, the primary investigator of the original study was consulted to discuss and confirm the themes that were identified. If necessary, these themes were modified under the guidance of the primary investigator. Consulting with the original researcher ensured the accuracy of the study findings. 
An audit trail was also used during this secondary analysis to establish rigor. According to Heaton (2004b), an audit trail is a detailed record of the research process. Maintaining an audit trail allows researchers to keep a record of their work and to ensure that the findings of the study are supported by the data (Heaton, 2004b). In this secondary analysis, an audit trail was used to record memos and all research decisions and activities, including data analysis procedures. Emerging themes related to harm reduction were recorded and continually modified throughout the analysis to support the accuracy of the study's findings.

Rigor was also achieved through reflective journaling. Researchers often use journaling to continually document and reflect on their personal biases and feelings that may impact the study (Szabo \& Strang, 1997). Since homelessness, mental illness, and addiction are considered relatively sensitive topics, it was necessary to frequently reflect on personal biases and prejudices that may have influenced the findings of this study. These reflections formed the basis of discussions with the primary investigator and thesis committee member to build the analysis. Overall, the use of triangulation, an audit trail, and a reflective journal (Szabo \& Strang, 1997; Heaton, 2004b) supported methodological rigor throughout this secondary analysis.

\section{Findings}

This study aimed to explore how Canadian veterans experiencing homelessness understand and experience harm reduction. Multiple themes were identified during the analysis of veteran focus group data including (a) Regimented Structure, (b) Understanding Both Worlds, (c) Congruent Recovery Journeys, (d) Location: Close Enough to Services, Far Enough from Harm, and (e) Harm Reduction is Housing Stability and Housing Stability is Harm Reduction. These themes represent the interface between military culture and homeless serving culture, which was conceptualized into a diagram (see figure 1). 


\section{The Interface Between Military Culture and Homeless Serving Culture Military Culture Homeless Serving Culture}

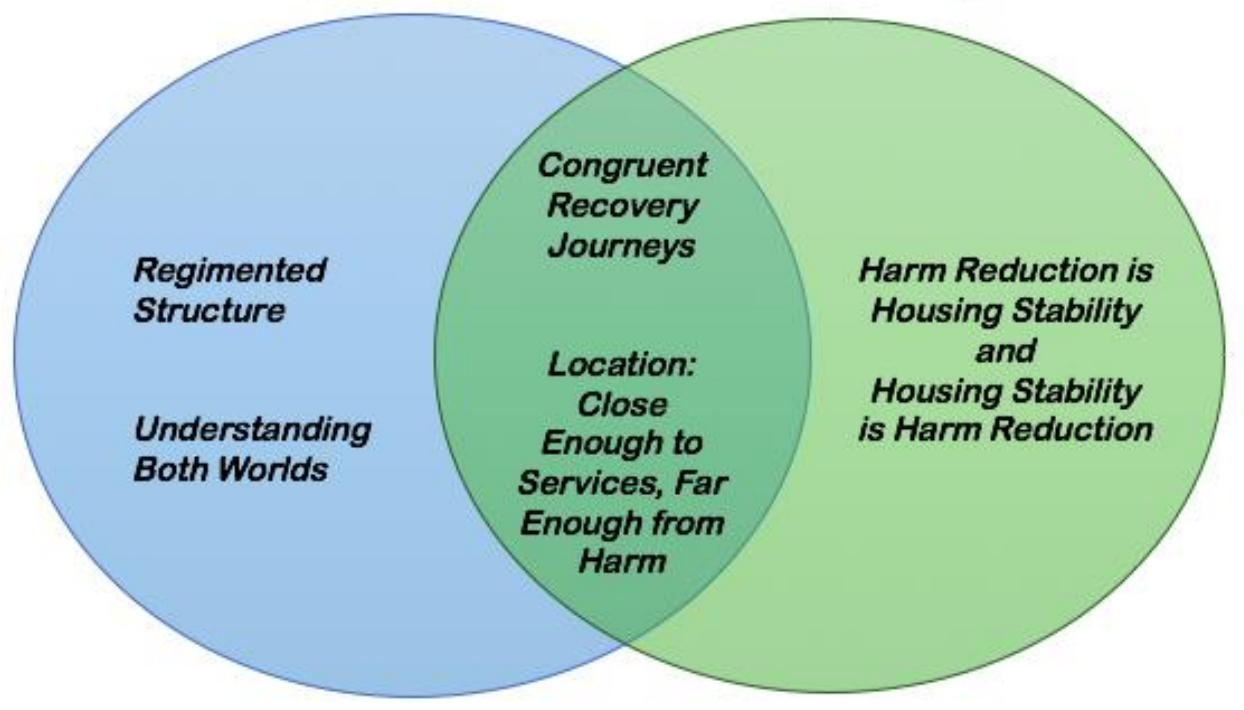

Figure 1. The Interface Between Military Culture and Homeless Serving Culture

\section{Regimented Structure}

The presence of a structured environment, or lack thereof, was identified as a significant theme across the focus groups. Within this theme, the term "structure" refers to the environment and management of the housing programs, not the physical structure of the buildings. Veterans often spoke of the highly structured nature and culture of military service. They frequently described the clear "chain of command", hierarchy, organization of time, and rules that were present in the military. As such, most of the veterans valued having a structured living environment, which was reflected in the experiences they shared during the focus groups. For some of them, this important sense of structure was lost or diminished when they exited military service. When they transitioned into the housing programs, the veterans also struggled to grasp and adjust to this sudden change in their living environment. One veteran told of his experience of transitioning from the shelter system into the housing strategy: 
It was a big transition for me because I had been doing the shelter thing, basically my lifestyle for the last few years. Where your meals are cooked for you, and all the rest of it kind of thing, so it was actually quite a big transition...Y You know, you've been in a structured environment for however long and all of a sudden you're kind of left to your own devices. So, that was a big one for me

Another veteran explained that transitioning into stable housing from a shelter or the streets can be a significant adjustment for veterans. He explained:

It's really easy, because like these guys were saying that, you know, you go from like having people around all the time that have a structured environment then all of a sudden your own place... You're not being forced to get up, go anywhere... and it's so easy just to like, sit in your apartment and just watch T.V. all day.

The lack of a structured environment created a significant challenge for the veterans when they transitioned into housing programs from the shelter system or streets. Some of them struggled to adjust to this drastic change in living arrangement and lifestyle.

Some veterans also reported frustration regarding the management of the housing programs. Often, it was unclear to the veterans who was responsible for managing and operating the housing programs, which was contradictory to the clear line of command and structure within the military. A veteran explained:

The place is getting more confusing all the time. That's what's happening. And I don't understand it because every time I've dealt with ex-military there's always been a chain of command and you know, a clear cut one.

In addition, veterans described the difficulties they experienced when trying to connect with support staff. In some cases, the veterans reported that the support workers were inaccessible and not "doing their job". In a focus group, a veteran described his experiences with his personal support worker. He explained:

I was given a personal support worker through the (name of organization). He's supposed to be making sure that I'm okay and that everything's going right. I never see the guy...I want him to at least do his job. Man, he doesn't even come up here. He's never around. And, I don't even think he's been around here. Like yeah he needs to just do his job. He's not doing it. 
Another veteran experienced a similar situation when trying to access his outreach worker:

When I need things, I'm finding that a lot of times I end up going and doing it myself, and of course I have to wade through all the bureaucracy, and I thought that that's what an outreach worker was, was somebody who could cut through all that red tape...You know how frustrating it is, especially for military guys to have to get to an appointment at 10 o'clock and not get seen until 11:30, you know, that kind of thing? I thought with having an outreach worker there, that she would be able to cut through all of that stuff...So, now I'm finding that I have to spend my days doing it. Where I had hoped that the outreach worker would be able to help me.

This veteran felt ultimately responsible for organizing his own resources, since his outreach worker was often inaccessible or absent. This experience also highlights the importance for veterans of adhering to a structured schedule. As this veteran explained, it can be incredibly frustrating for them when support staff miss or are late to scheduled meetings and appointments.

Conversely to concerns regarding the lack of rules, structure, or schedules was the veterans' strong appreciation for rules where they existed within the housing programs. Across the focus groups, most of the veterans agreed that the enforcement of a set of rules is beneficial. One veteran explained that it would "be chaos" without the implementation of regulations to manage the housing programs. This significant desire for rules and regulations often stemmed from the veterans' highly disciplined military background. For some of the veterans, the presence of rules also created a sense of comfort as well as accountability for their substance use. Two veterans who were experiencing substance use issues reported:

Well for me, I need some accountability and you know I need some sort of structure 'cause with addictions we're basically undisciplined.

I believe what would be beneficial to me, is a set model of um, rules and regulations and structures, [but] not in a hard-core, heavy handed way.

Many of the veterans also recommended that there should be consequences for individuals who violate the housing rules. They believed that breaching these rules, such as 
smoking or drinking indoors, could negatively impact the veterans who are recovering from a drug or alcohol addiction. Two veterans explained:

Just make sure there are boundaries that you cannot cross, like there has to be consequences. Um...drinking, smoking inside the building... There just has to be some boundaries that can't be crossed. It's detrimental to the other veterans that are in there, so we have to make sure that we take care of that situation.

You have to have structure and consequences, eh? You only give so many people so many chances, and if they still keep on wrecking up, get rid of them.

Veterans often reported that the presence of rules and regulations can create and maintain structure within housing programs. Additionally, some of them felt that disciplinary action was necessary if these rules were broken, since the well-being and recovery of other veterans was violated.

The veterans shared their challenges of transitioning from the shelter system into stable housing. For some of them, the sense of structure that they value as ex-service members was diminished during this critical transition period. Without a clear structure in place, some of the veterans struggled to adjust to this drastic change in lifestyle and living arrangement. Other veterans reported that some of the support and management staff were often inaccessible. Consequently, they had trouble accessing the resources they needed. To maintain structure within the housing strategy, the veterans also recommended the implementation of rules and regulations. However, they strongly agreed that there should be consequences and penalties for individuals who fail to adhere to these rules.

\section{Understanding Both Worlds}

The veterans frequently spoke of the importance of interacting with individuals who understood not only the experience of being homeless, but also the military culture. This preference often originated from the comradery they experienced with other service members 
during military service. However, relationships and social gatherings among military personnel often involved alcohol use. The veterans referred to the high accessibility and acceptance of alcohol within the military. In some cases, alcohol consumption was encouraged and expected of them as military members. Two veterans explained that "it [alcohol] was promoted in the army" and "if you didn't drink you were an outcast." Another veteran also reported:

And it's accepted [alcohol use]. Um, I don't know about now but back when I was there, you'd go to the bar on the base and it's cheaper.

Although drinking was common and facilitated comradery during service, it often contributed to the substance use and addiction issues many veterans experienced after exiting the military. Despite this dilemma, most of the veterans expressed the importance of living and associating with other veterans. For many of them, being surrounded by other veterans re-establish the commonality and comradery associated with military service. The veterans often explained that the military culture is unique, so living with people who shared similar experiences and understood the distinctive language was essential. Having a common understanding of the military culture created a connection among the veterans and facilitated emotional support. As one veteran reported: "You're with people who understand at least $90 \%$ of what you're talking about". Two veterans explained:

So, going into a house, into an environment where people understand those experiences, that's, you know, a big deal. So, you say something to someone, and they understand.

I can sit down and have a beer with any one of these guys in this room. [The] comradery that comes with it, you get that feeling again once in a while. I mean, it might have been twenty years ago, thirty years ago, that you actually [served in the military] but you still get that feeling, you know? You belong to something. When you're on the street you don't belong to anything... But in this building at least everybody here has served in one form or another.

Although interacting with other ex-military members was important to the veterans, not all of them experienced the same degree of connection while living in the housing programs. 
Two sites offered private sector apartments that were scattered within the local communities.

Some of the veterans who lived independently lacked a close association with other ex-military members. Although they enjoyed the sanctuary and privacy of having their own space, they often felt lonely or isolated in their apartments. Therefore, they recommended that there be more opportunities for them to meet as a group to develop relationships with other veterans. A veteran who lived in private apartment explained:

You'd at least have somebody to talk to. We have those problems being isolated, its difficult because everything goes in your head and you can't stop it... Just to allow us the opportunities to at least meet each other...

Most of the veterans also described the importance of having staff members who understood the military culture and language. However, some of the support at the housing programs was provided by staff or volunteers without a military background. Therefore, the veterans often felt that these staff did not fully understand their unique military background, language, and experiences. Consequently, it was difficult for them to relate to staff members and develop effective relationships with who was helping them. Therefore, many of the veterans recommended that support staff have a military background or a basic understanding of the unique culture. A veteran explained:

We could use somebody that could understand where we come from. Someone who has had a bit of a military background themselves. We're so used to it that we talk a certain way. We use certain terms, certain people like me who did 37 odd years in reserves. So, that they understand some of the vocabulary we use. I'm so used to saying certain things in certain ways that it confused poor old (name of support worker) sometimes.

Furthermore, at some of the housing sites, there was frequently a large age difference between the veterans and the staff. Consequently, a general disconnect often existed among the veterans and staff members. In many cases, the veterans felt that the younger staff did not fully 
understand or respect their military background. Furthermore, placing younger staff members in positions of authority lessened the veterans' senses of dignity and pride. Two veterans stated:

I mean, I understand economics, but when you have a 20-year-old yelling at you "don't do this, don't do that" it gets a little annoying.

Well I'm 63 and I'm getting told I can't do this by a 21-year-old? Who's never been in a position of authority ever before in their life. You know, I just walk away, I don't say anything because I just get written up.

To reduce this incompatibility, the veterans suggested recruiting support staff who are older in age and understand the military culture. Some of them were unable to relate to the younger staff members due to the lack of commonality between them. However, the availability of peer support at some of the housing programs bridged this incompatibility and provided the opportunity for the veterans to interact with people they could relate to.

During the focus groups, the value of peer support was often highlighted and discussed. Two of the housing sites offered peer support through Operational Stress Injury Clinics (OSIs), which were established by the Department of National Defence and the CAF to assist and support veterans and their families (Government of Canada, 2017). At one of these sites, peer support was also provided informally by veteran volunteers. This type of support fulfilled the veterans' need to interact with individuals who understood their unique military background and experiences. Furthermore, it assisted them on their recovery from substance use. Many of the peer supporters had struggled with addiction in the past, so they could relate to the veterans easily. The veterans expressed that it can be extremely difficult for them to interact with support staff who had never experienced a substance use disorder in their lifetime. Two veterans explained:

If you're not an alcoholic, you can't tell an alcoholic how to become sober and (name of worker) is a veteran and he understands us. That is important, to know where we are 
coming from. If you were never an addict or an alcoholic, I don't care what you say, you have no clue. We gotta relate to who's helping us.

It's easier to talk to somebody who knows and has been there. If you were an alcoholic, you can't talk to somebody who's never touched a drop of alcohol because they just don't understand what's going on.

Additionally, local police associations were often a source of peer support for the veterans. These police officers were often former military members, so they could connect with the veterans more deeply. For example, at one of the sites, a police officer regularly escorted a group of veterans to go site-seeing and watch professional hockey games. As such, interacting with these police officers was a tremendous source of peer support for the veterans. Unlike other homeless populations, the veterans were comforted by a uniform. Therefore, the veterans frequently recommended that police officers be involved as peer supporters at future veteranspecific housing programs. A veteran explained:

Oh, I would say the first thing is go over to the police, not because of the people that are coming in, it's that a lot of those guys are veterans [and] are so, so supportive! They are incredible. But that's why I mentioned get a hold of them because a lot of those guys are veterans.

Across the focus groups, the veterans often expressed their desire to interact with individuals who had also experienced military service, homelessness, and substance use issues. Associating with other veterans, including peer supporters and police officers, re-created the commonality and comradery associated with military service. Furthermore, it assisted the veterans during their recovery from homelessness and substance use. Many of them, especially those living independently in private apartments, recommended offering additional peer support services. As one veteran explained: "You need to find people you can relate to, and who can relate to you." 


\section{Congruent Recovery Journeys}

The housing models differed between each of the four sites and included two-bedroom units in a private building; one-bedroom units in an building intended for male veterans; two or three-bedroom units with shared common spaces within a single building; and independent, private-sector scattered apartments (Forchuk \& Richardson, 2015). The veterans often expressed their concern about sharing accommodations with individuals who were at varying stages of recovery. Although some of the veterans enjoyed the comradery associated with shared units, issues frequently occurred when roommates were incompatible with one another. In many cases, the source of this incompatibility was related to addiction and substance use issues. For instance, veterans who were attempting to remain sober were often placed with individuals who were actively engaging in substance use. Poorly-matched roommates often lead to significant tension and conflict, which was detrimental to the veterans' well-being. Two veterans described their negative experiences:

I mean, I've lived in shared accommodation...30 roommates later in four years and I've had all these people with schizophrenia and they're all poking up [on] the streets. Another guy smoking crack at like 9 A.M. or drinking like crazy, we have nothing in common.

You've got some hard-core alcoholics. I've been sober for fourteen years. So, you've got your pothead, you've got your crackhead, [and] heavy boozer that's drunk all the time. And it's not going to change. I would say, if you can, divide them up...The drunks with the drunks. The crack-heads with the crack-heads...Like, I'm on sleeping pills because I have to be to sleep here...I'm a light sleeper and their drunkenness that goes on around cheque week is unbelievable. But that's no way to live either, popping pills so you can live in a place.

These experiences have shown that living with individuals who engaged in substance use negatively impacted the veterans' who were practising sobriety. In some cases, these differences between roommates resulted in their separation. They were either placed in different apartments or chose to move out of the building altogether. Not only did this change in living environment 
damage the veterans' recovery process, but it also contributed to housing instability. Therefore, most veterans preferred living independently, especially in accommodations where substance use was permitted. The veterans strongly agreed that future housing programs should ensure that individuals are compatible prior to pairing them together. Matching individuals who were at different stages of recovery created tension, conflict, and instability. One veteran explained: "They have to take into consideration that there are some people that just can't cohabitate."

\section{Location: Close Enough to Services, Far Enough from Harm}

The location of the housing programs varied between each of the sites. For instance, some of the sites were located centrally, whereas others were situated in more quiet and secluded areas. The location of the programs was integral to both the well-being and recovery of the veterans. For those who lived in less-central areas, location was often a major barrier to accessing important resources. The veterans explained that many of the resources they access, such as grocery stores and health care providers, are primarily in central locations. Without a car or money to book a taxi, it was extremely difficult for the veterans to travel to these services.

One veteran explained: "We can't function like everybody else and we have restrictions. Like we have no car, or money to get taxis." In many cases, the veterans had to take multiple buses to get to where they needed to go, which could take roughly one to two hours. Two veterans reported:

I found that I was stuck in the middle of nowhere.... Like half the services that I access here are all downtown. Having to find those services in (city name) and (city name) takes some time.

[You need] something more central. I mean, it's great that they've got something out in (city name). But, there should be something here [downtown] because a lot of doctors are here, you're going to grab the people who are downtown, and that's the area they know is downtown. And I think that would be better.

In some cases, the veterans were unable to access the resources that were essential to their recovery from substance use and addiction. For example, a veteran spoke of how he was unable 
to travel to the OSI clinics to receive the veteran-specific supports he needed, since the distance was too far. He explained:

The OSI guys are like five miles out. It takes you an hour and a half to get there by bus and you have to go by bus because the staff won't take you there. That's why I don't want to see the OSI guys, it takes two hours to get there to see them and two hours back.

Although living in less-central locations created a barrier to accessing services, most of the veterans agreed that future housing programs should not be in the downtown cores. In their opinion, these areas should be avoided due to the dangers and "temptations" found there. For some of them, living in quieter neighbourhoods also reduced their fears of being robbed or attacked on the street. Furthermore, they often spoke of the high availability of drugs and alcohol within downtown cores. Referring to downtown, one veteran explained: "Every block there's a liquor store or someplace where you can get alcohol." Living in these areas where substance use is widespread could be devastating to veterans who are recovering from an addiction. Some of them referred to downtown as "the belly of the beast" and "skid row." One veteran elaborated:

I lived in (name of city) for a while and anyone would want to tell you it's a nasty place. But this area is really good 'cause we got access to (name of grocery store) on the corner and we're kinda central in the middle of the two major train stations. It's a little way but I think we're really in a great spot, it's better to put the men in a place like here instead of downtown. I used to like downtown but not anymore. Downtown, like I said, it a lot of pests and bugs and here it's very clean and also less temptations, even though I never used drugs or alcohol.

These experiences have highlighted the importance of the location of housing in relation to the veterans' recovery. Being situated in areas that are far away from essential services and resources created a significant barrier. Conversely, housing located in downtown cores negatively impacted those who were recovering from substance use and addiction issues. Therefore, most of the veterans recommended that future housing sites be located centrally, but 
far enough away from downtown. This proposed location would not only facilitate access to essential resources, but also prevent exposure to substance-related harms.

\section{Harm Reduction is Housing Stability and Housing Stability is Harm Reduction}

Analysis of focus group data revealed various significant findings related to harm reduction as well as Housing First. During each focus group, the veterans were asked to share the strengths of the housing programs. Many of them described the importance and necessity of implementing harm reduction and Housing First to facilitate permanent housing. A veteran reported:

Harm reduction. That's very essential, right? We all come from a military background. We've got a lot of different issues and you put a bunch of us together, a bunch of different trades. It's different than civilian life, there's a lot of angers and a lot of different abuse and things that we've gone through.

The veterans often reported that harm reduction and Housing First created stability in their lives. In their opinion, securing stable and permanent housing should be the first step in the recovery process. As one veteran explained: "A stable house [first] and everything else needs to roll after that." Having a stable home provided access the resources and supports that the veterans needed. For example, a veteran explained that it can be difficult for support workers and programs to contact them without a permanent address. He stated:

It all starts with a stable home, because if they can't contact you, there's no way...If you have no location to go to, you have nothing... And nobody can get a hold of you to get to these veteran programs if you don't have a place to stay, if you don't have access to a phone or a roof over your head.

Being homeless also limited the employment opportunities for the veterans. One veteran expressed that potential employers were hesitant or unwilling to hire homeless individuals. However, with a permanent address, this barrier was reduced since the veterans were no longer being overlooked due to the stigma associated with being labelled as "homeless". He explained: 
We've got a permanent address now, and that makes a difference. We've got a phone number, we've got an address. Where if we were on the streets and you were looking for a job, they'd phone the place that you gave the number to, and right away you're homeless. [They're] not even looking at you, and you're out.

Many of the veterans spoke of how harm reduction and Housing First gave them additional time to address their personal issues. When these veterans were homeless, most of their days were spent worrying about meeting their basic needs and where they were going to stay for the night. There was little time available for these veterans to address the issues they were experiencing; they were in a constant state of survival. However, securing a permanent address reduced some of the persistent worrying that these veterans experienced while living on the street or in shelters. Many of the veterans expressed that they were no longer concerned about finding a "safe place" to live when they enrolled in the housing programs. Referring to stable housing, one veteran reported: "It gives you the time. You're not spending 9 or 10 hours a day trying to get your basic needs me - they're already met.” Another veteran explained:

It takes $90 \%$ of the worry that you have about where you're going to be every morning. So, without that worry, now you can concentrate on "I'm an addict" myself and you can concentrate on trying to clean up and get your life back together because you're not concentrating on trying to survive out there (the streets) all the time.

For many of these veterans, achieving stable housing was an essential component of their recovery. Harm reduction facilitated stability and allowed the veterans' the opportunity to address their personal issues, including substance use. Rather than focusing on survival, the veterans could concentrate on recovering from an addiction. In some cases, harm reduction strategies changed the types of substances that were used by the veterans. A veteran reported:

I find that one good thing for myself, when I came here, I was off the street. And I was drinking all kinds of shit, I mean all kinds. But, through the harm reduction thing I was able to cut down to just regular alcohol. 
Stable housing also eliminated the safety issues that some of them experienced while living on the streets or in shelters. They often described the unsafe conditions of both the street and shelter environments. In many cases, the veterans were victims of both violent and nonviolent crimes, including theft and physical assault. However, the housing programs protected them from the dangers associated with homelessness. A veteran explained:

(Name of housing program) is pretty safe and secure, it's got to be. I think it's really important. Especially when you are out in the bush, where you are constantly keeping all your stuff [close to you] because somebody's gonna steal it...Y You have a place where it's your own, you can lock it up, you don't have to worry about stuff getting stolen, or getting beat up, or whatever.

Having a safe place to live was essential to the veterans' recovery. Enrolling in the housing programs reduced or eliminated the stress and risk associated with living on the streets or in shelters. In stable housing, the veterans were no longer worried about finding a sanctuary from violence and danger.

These experiences have demonstrated that harm reduction was a necessary component of the veteran-specific housing programs. Not only did a permanent address create stability in the veterans' lives, but it also established a sense of safety. Furthermore, having a place of their own provided the veterans the opportunity to address their housing and substance use issues.

\section{Discussion and Implications}

The findings of this study are often consistent and, at times, contradictory to the current Canadian and international evidence on veteran homelessness and harm reduction. The theme Regimented Structure revealed that the veterans preferred living in a highly structured environment, which often originated from the clear and consistent rules and practices that are engrained in military service. However, this important sense of structure was often lost when the veterans exited military service; many of them struggled to cope with this sudden change in 
living environment. This finding is consistent with Canadian literature (Ray and Forchuk, 2011; Black, Westwood, and Sorsdahl, 2007) which has shown that veterans often experience a loss of structure after leaving military service. Furthermore, Ray and Forchuk (2011) found that it can be difficult for veterans to cope with the transition from military to civilian life. Consistent with this study's findings, research in the U.S. (Molinari, Brown, Frahm, Schinka, \& Casey, 2013) has found that structured housing supported veterans' recovery from homelessness. The veterans in this study reported that having a regimented structure within their living environment was essential to their recovery. However, this finding is somewhat unique to the veteran population. For example, Canadian research revealed that youth experiencing homelessness were often critical of the strict rules and regulations that are enforced at shelters and housing programs (Krusi, Fast, Small, Wood, \& Kerr, 2010). Although structured housing was important to the veterans, there were often various structural issues within the housing programs.

Some of the veterans had trouble connecting and communicating with support staff and, consequently, did not receive the services they needed. In the U.S., Cusack and Montgomery (2018) found that veterans who lived in a supportive housing program often experienced difficult interactions with staff due to poor communication, which is consistent with the study findings. In this study, many of the veterans also desired rules and discipline to establish structure, which often originated from their strict military background. The culture of the Canadian military consists of a set of values and practices that its members are bound to follow. If this high standard of behaviour and conduct is not adhered to, they are disciplined accordingly (Capstick, 2003). The veterans often felt that residents who used substances indoors should be disciplined, despite the presence of harm reduction programming at some of the sites. However, this finding is contradictory to the harm reduction philosophy. Harm reduction does not require abstinence, 
nor does it involve the discipline of those who continue to use substances (Erickson et al., 2002;

Thomas, 2005). Therefore, veteran-specific Housing First programs may need to consider how to incorporate structure for veterans in a way that is not incongruent with harm reduction. Residents who use substances should not be disciplined or evicted if a true harm reduction philosophy is followed. To create structure, the roles of housing and support staff could be clearly defined to ensure that the veterans have access to the resources they need to address their substance use. Furthermore, veterans could be directly involved in the operation of the housing programs by being assigned meaningful roles, such as maintenance or kitchen staff. Harm reduction principles do not have to be violated to establish structure.

The theme Understanding Both Worlds revealed that the veterans preferred to interact with individuals who understood the both military culture and the experience of homelessness. During the focus groups, many veterans spoke of the comradery they experienced while in the military. However, excessive alcohol consumption was common during service, and it contributed to the veterans' substance use issues and, ultimately, housing instability. This finding is consistent with Canadian (Ray \& Forchuk, 2011; Lee \& Hachey, 2011; Richer, Lee, \& Born, 2016) and U.K (Milroy, 2001; Johnsen et al., 2008; Milroy, 2009) research that has shown that alcohol use is common in the military and may contribute to substance use issues later. Despite this negative association, relationships with other ex-service members remained extremely important to the veterans.

The veterans highly valued the veteran-to-veteran peer support that was offered at some of the housing programs. For many of them, interacting with peer supporters who had a military background and personal experience with substance use was vital to their recovery. This finding is consistent with a Canadian study by Allman et al (2007), which found that people who used 
drugs developed the most effective relationships with providers who had personally experienced a drug addiction (Allman et al., 2007). Furthermore, literature in the U.S. (Resnick \& Rosenheck, 2008; Travis et al., 2010; Tsai \& Rosenheck, 2012; O’Connell, Kasprow, \& Rosenheck, 2016; Resnik, Ekerholm, Johnson, Ellison, \& O’Toole, 2017) found that peer mentorship resulted in several positive outcomes for veterans including increased levels of social support, greater quality of life, improved psychological health, and empowerment. The veterans in this study often suggested that police associations be involved as peer supporters at the housing programs, since some officers also identify as veterans. Historically, Canadian law enforcement practices, such as the confiscation of injection materials, have negatively impacted individuals who use substances (Werb et al., 2008). In this study, however, police officers were a source of support for the veterans, which is inconsistent with the traditionally difficult relationship between law enforcement and people who use substances. Although police involvement may be inappropriate for other key populations experiencing homelessness, it may be beneficial and effective within the veteran population. The findings of this study are also consistent with the current evidence on peer support as a model for housing stability and recovery.

Canadian (Coatsworth-Puspoky, Forchuk, \& Ward-Griffin, 2006; Forchuk, Reynolds, Sharkey, Martin, \& Jensen, 2007; Bouchard, Montreuil, \& Gros, 2010; Kidd et al., 2014; Forchuk \& Richardson, 2015) and U.S. (Boisvert, Martin, Grosek, \& Clarie, 2008; Bean, Shafer, \& Glennon, 2013; Gidugu et al., 2014) research has commonly cited peer support as both an effective evidence-based recovery model and housing stability model. For instance, a study in the U.S. found that peer support, in combination with harm reduction and Housing First, resulted in improved quality of life and reduced substance use among individuals experiencing homelessness (Bean et al., 2013). Similarly, a Canadian study by Kidd et al (2014) showed that 
psychiatric patients who received peer support experienced greater levels of functioning, community integration, and quality of life. Additional research in Australia (Lawn, Smith, \& Hunter, 2009) and the U.K. (McLean, Woodhouse, Biggs, \& Bowie, 2012; Cyhlarova et al., 2015) has also demonstrated the benefits of peer support for individuals living with mental illness. Supplementing this evidence, this study has further revealed that peer support can produce positive outcomes for people recovering from homelessness and substance use, including veterans. Veteran-specific housing programs may need to further explore how to integrate peer support into services, especially in private accommodations where it is not as readily available. Forchuk and Richardson (2015) developed the Peer Program Practice Guide, which provides recommendations on how to incorporate peer support programming into Housing First for veterans. For instance, the guide suggests that Housing First programs require an organized structure and clearly defined staff roles to successfully implement peer support. Furthermore, staff may need to contact the appropriate organizations, such as local Royal Canadian Legion offices or police services, to recruit suitable peer mentors for veterans. Overall, connecting with individuals with similar experiences may support veterans to achieve housing stability (Forchuk \& Richardson, 2015).

The theme Congruent Recovery Journeys has demonstrated that veterans preferred living independently, since issues between roommates often occurred due to substance-related issues. In many cases, the veterans living in shared accommodations were matched with individuals who were at a different stage of recovery, which often resulted in conflict. This finding is consistent with Canadian (Forchuk, Nelson, \& Hall, 2006; Piat et al., 2008), U.S. (Strebnik, Livingston, Gordon, \& King, 1995; Tsai, Bond, Salyers, Godfrey, \& Davis, 2010), and Australian (Browne \& Courtney, 2005; Warren \& Bell, 2008) literature which has shown that the majority of mental 
health service consumers prefer to live independently. Within the veteran population, U.S. literature (Schutt, Weinstein, \& Penk, 2005) has also found that most homeless veterans with dual diagnoses prefer to live alone, but with on-demand staff support. As such, veterans may benefit from either living independently or with individuals who are at the same recovery stage. If shared accommodations are offered, Housing First programs should ensure that roommates are compatible and matched based on their recovery stage. This finding also emphasizes the need to consider veterans' choices and preferences in their housing, which is consistent with the aim of the Housing First approach (Gaetz et al., 2013).

The impact of the location of the housing programs on the veterans' well-being and recovery was highlighted in theme Location: Close Enough to Services, Far Enough from Harm. Living in less-central locations made it difficult for them to travel to inner cities where essential services were located. This finding is congruent with Hardill's (2014) study, which showed that transportation to services and resources, including harm reduction facilities, is a significant barrier for substance users living in secluded and rural areas of Canada. Similarly, Tsai, Ramaswamy, Bhatia, and Rosenheck (2015) also found that access to services and resources can be a challenge for veterans who are homeless and living in the rural U.S. The veterans in this study felt that placing housing in the downtown cores of cities was inappropriate due to the high availability of substances in these areas. Consistent with this finding, research in Canada (Bozinoff, Small, Long, DeBeck, \& Fast, 2017) has found that accessing harm reduction services in downtown cores can place abstinence and sobriety at risk. As such, the location of housing may need to be considered to ensure veterans' access to essential resources and avoid substancerelated harms. Canadian and international research has also demonstrated the effectiveness of harm reduction in facilitating stable housing and reducing the harms of substance use. 
This study has shown that harm reduction may address homelessness and substance use among Canadian veterans. The theme Harm Reduction is Housing Stability and Housing Stability is Harm Reduction demonstrated that having a home established stability and safety in the veterans' lives. Harm reduction also supported the veterans on their recovery from substance use. These findings are consistent with the current research on harm reduction and Housing First in Canada and internationally. The ability of harm reduction to reduce the harms of substance use is commonly cited in the Canadian literature (Buxton, Kuo, Ramji, Yu, Krajden, 2010; Nolan et al., 2015; Vallance et al., 2016; Petrar et al., 2016). Canadian studies assessing the effectiveness of Housing First found that it leads to housing stability and improved health outcomes (Krause, Serge, \& Goldberg, 2005; Goering et al., 2014). Furthermore, Bourque et al (2015) found that Housing First resulted in increased social functioning and improved quality of life among Canadian veterans experiencing homelessness and mental health challenges.

Several studies in the U.S have also evaluated Housing First among individuals experiencing homelessness and substance use, including veterans (Davidson et al., 2014; Montgomery, Hill, Kane, \& Culhane, 2013). Consistent with this study, Montgomery et al (2013) found that Housing First interventions lead to increased housing retention and decreased substance-related harms among veterans. Recent research in England, Denmark, the Netherlands, Scotland, and Portugal has also shown that Housing First can result in several positive outcomes, including improved housing stability and reduced substance use (Please \& Quilgars, 2013; Wewerinke, al Shamma, \& Wolf, 2013; Benjaminse, 2013; Johnsen, 2013; \& Ornelas, 2013). Overall, the findings of this study suggest that harm reduction may effectively address veteran homelessness, which may have many implications for policy, Housing First programs, nursing practice, nursing education, and research. 
The findings of this study may be used to inform the development of policies to address and prevent veteran homelessness in Canada. Many of the veterans reported that their alcohol use during military service contributed to their housing issues. This finding supports the implementation of additional policies and programming to assist service members and veterans experiencing addiction; ultimately, these resources may prevent the slow descent into homelessness. According to Gaetz et al (2016), preventing homelessness may require addressing the needs of key homeless groups, including veterans. This study has shown that veterans have unique needs that are distinct from other homeless populations. Specifically, there was an interest among many of them for more structured and supportive housing arrangements that somewhat mimicked the structure of the military lifestyle, including the presence of rules. Therefore, the challenge for veteran-specific Housing First programs is to implement this structure in a way that is not at odds with the flexibility inherent in a harm reduction model and still meets people where they are at.

This study may also have several implications for nursing practice. The findings have shown that veterans require support and housing workers who are easily accessible. As such, nurses can work with veterans to ensure that they have access to essential resources and services. Various organizations, including the Royal Canadian Legion and police associations, were involved at some of the housing programs (Forchuk \& Richardson, 2015). Nurses can collaborate with these groups to effectively respond to veteran homelessness. Lastly, nurses must advocate for ethical policies (Canadian Nurses Association, 2018) that address the needs of veterans experiencing homelessness. With respect to nursing education, curricula should highlight the role of harm reduction in addressing homelessness and the harms of substance use. Students must understand the harm reduction philosophy, since they will likely care for 
individuals experiencing homelessness and substance use disorders. Furthermore, veterans often expressed their frustration at staff's lack of understanding of the military culture. Therefore, nursing education should teach students about this unique culture to enable them to provide care that meets the needs of veterans.

This study has further revealed the nature of veteran homelessness in Canada. However, additional research is needed to explore how harm reduction can support the need for veterans to live in structured housing and connect with the military culture. Research initiatives should be completed as a participatory process with veterans, since it may empower them to address the inequities that have contributed to their challenges (Baum, MacDougall, \& Smith, 2006). Studies examining harm reduction among veteran subgroups, such as women and the Indigenous people, may also be beneficial. Overall, the findings of this study may influence how policies, Housing First programs, nursing practice, nursing education, and research prevent and address veteran homelessness.

\section{Limitations}

This study has contributed to the very limited research on veteran homelessness in Canada. Furthermore, this is only study identified that has explored how Canadian veterans perceive and experience harm reduction as a component of stable housing. Various limitations existed in this study that may have influenced the findings. Firstly, analysis of focus group data may have impacted the results of this study. In the primary study, veterans were given the choice to participate in the focus groups, so the opinions of those who chose not to attend these meetings were not included. As non-participants were not questioned regarding their choice, there is no data available on what influenced participation in the focus groups. Nevertheless, a 
large portion of the veteran sample attended the initial $(n=24)$, mid-cycle $(n=24)$, and final focus groups $(n=39)$.

A further limitation of this study was the dominantly white, male sample. In the primary study, the sample consisted of $92 \%$ males and $8 \%$ females. Of this total sample, only three female veterans participated in the focus groups. Considering that $87 \%$ of CAF veterans identify as male (MacLean et al., 2013), this low participation of female veterans is not surprising. Nonetheless, the participation of predominately male veterans excluded the unique experiences of their female counterparts. Furthermore, only $9.7 \%$ of the participants identified as Aboriginal or Metis. As such, the findings of this study may not reflect the experiences of female, Aboriginal, or Metis veterans. Future research is needed to explore specifically how other veteran groups experiencing homelessness perceive harm reduction.

The veterans' limited understanding of harm reduction was also a limitation to this study. Analysis of focus group data revealed that this strategy was an essential component of stable housing for the veterans. However, some of them inaccurately described harm reduction and believed this approach enforced a limit on substance use. Furthermore, they often felt that the success of harm reduction was dependent on individuals' willingness to achieve abstinence, which is contrary to this philosophy (Gaetz et al., 2013). As such, despite the perceived benefits of harm reduction, a general misunderstanding of this approach existed among the veterans. Therefore, the findings of this study were limited by the veterans' inaccurate understanding of harm reduction.

The use of a secondary analysis was another limitation of this study, since it was limited by the purpose of the original study. The aim of the original study was not to explore harm reduction, but to evaluate the various housing programs (Forchuk \& Richardson, 2015). As such, 
this study was limited by the questions that were asked during the focus group discussions (see Appendix C). Furthermore, this study did not involve prolonged contact with the veterans in the 'field', which is referred to as the issue of "not having being there" (Heaton, 2004a, p. 60). An important component of qualitative research is immersing oneself in the social situation being studied (Dale, Arbor, \& Proctor, 1988). Therefore, a deep understanding of the veterans' experiences may not have been fully achieved in this secondary analysis. Further research is needed to explore harm reduction among CAF veterans experiencing homelessness.

\section{Conclusion}

This study has confirmed that veterans are a unique population at risk of homelessness and that harm reduction is an important part of Housing Fist for veterans. Analysis of focus group data from The Canadian Model for Housing and Support of Veterans Experiencing Homelessness study (Forchuk \& Richardson, 2015) revealed that veterans' experiences with harm reduction are influenced by the interface between military and homeless serving culture. Various themes emerged during this study which captured the veterans' understanding of harm reduction including (a) Regimented Structure, (b) Understanding Both Worlds, (c) Congruent Recovery Journeys, (d) Location: Close Enough to Services, Far Enough from Harm, and (e) Harm Reduction is Housing Stability and Housing Stability is Harm Reduction. The findings of this study have demonstrated that CAF veterans have housing and addiction needs that are distinct from the general homeless population. Specifically, harm reduction was essential for the veterans since it created stability, safety, and structure in their lives. Nurses, institutions, and governments can utilize these findings to ensure that this groups' unique housing and addiction needs are adequately addressed. 


\section{References}

Allman, T. D., Myers, J., Schellenberg, C., Strike, R., Cockerill, R., \& Cavalieri, W. (2007). Improving health and social care relationships for harm reduction. International Journal of Drug Policy, 18(3), 194-203. doi: 10.1016/j.drugpo.2006.07.005

Baum, F., MacDougall, C., \& Smith, D. (2006). Participatory action research. Journal of Epidemiology and Community Health, 60(10), 854-857. doi: 10.1136/jech.2004.028662

Bean, K. F., Shafer, M. S., \& Glennon, M. (2013). The impact of housing first and peer support on people who are medically vulnerable and homeless. Psychiatric Rehabilitation Journal, 36(1), 48 - 50. doi: 10.1037/h0094748

Benjaminsen, L. (2013). Rehousing homeless citizens with assertive community treatment: Experiences from an act-programme in Copenhagen. Copenhagen, Denmark: SFI - The Danish National Centre for Social Research. Retrieved from https://pure.sfi.dk/ws/files/232672/WP_07_2013.pdf

Black, T.G., Westwood, M.J., Sorsdahl, M.N. (2007). From the front line to the front of the class: Counseling students who are military veterans. In J. Lippincott \& R.B. Lippincott (Eds), Special Populations in College Student Counseling (3-20). Virginia, U.S.: American Counselling Association. Occupational Therapy International, 15(4), 205-220. doi: $10.1002 / o t i .257$

Boisvert, R. A., Martin, L. M., Grosek, M., \& Clarie, A . J. (2008). Effectiveness of a peersupport community in addition recovery: Participation as intervention.

Bouchard, L., Montreuil, M., \& Gros, C. (2010). Peer support among inpatients in an adult mental health setting. Issues in Mental Health Nursing, 31(9), 589-598. doi: $10.3109 / 01612841003793049$ 
Bourque, J., VanTil, L., Gibbons, C., LeBlanc, S., Landry, A., LeBlanc, J.,...More, F. (2015). Impact of a housing first intervention on homeless veterans with mental illness: a Canadian multisite randomized controlled trial. Journal of Military, Veteran, and Family Health, 1(2). doi: 10.3138/jmvfh.2985

Bourque, J., VanTil, L., LeBlance, S. R., Kopp, B., Daigle, S., LeBlanc, S., .. More, F. (2014). Correlates of veteran status in a Canadian sample of homeless people with mental illness. Canadian Journal of Community Mental Health, 33(4), 141-159. doi: 10.7870/cjcmh2014-031

Bozinoff, K., Small, W., Long, C., DeBeck, K., \& Fast, D. (2017). Still “at risk”: An Examination of how street-involved young people understand, experience, and engage with "harm reduction" in Vancouver's inner city. International Journal of Drug Policy, 45, 33-39. doi: 10.1016/j.drugpo.2017.05.006

Browne, G., \& Courtney, M. (2005). Exploring the experience of people with schizophrenia who live in boarding housing or private homes: A grounded theory study. Contemporary Nurse, 18(3), 233-246. Retrieved from https://www.tandfonline.com/loi/rcnj20

Buxton, J., A., Kuo, M. E., Ramji, S., Yu, A., \& Krajden, M. (2010). Methadone use in relation to hepatitis C virus testing in British Columbia. Canadian Journal of Public Health, 101(6), 491-491. Retrieved from https://journal.cpha.ca/index.php/cjph

Canadian Institute for Health Information. (2007). Improving the health of Canadians: Mental health and homelessness. Ottawa, ON: Author. Retrieved from https://secure.cihi.ca/free _products/mental_health_report_aug22_2007_e.pdf 
Canadian Nurses Association. (2017). Code of ethics for registered nurses. Ottawa, ON: Author. Retrieved from https://www.cna-aiic.ca/ /media/cna/page-content/pdf-en/code-of-ethics2017-edition-secure-interactive

Capstick, M.D. (2003). Defining the culture: The Canadian army in the $21^{\text {st }}$ century. Canadian Military Journal, 4(1), 47-53. Retrieved from http://www.journal.forces.gc.ca/arc/indexeng.asp

Carlson, E.B., Garvert, D.W., Macia, K.S., Ruzek, J. I., \& Burling, T.A. (2013). Traumatic stressor exposure and post-traumatic symptoms in homeless veterans. Military Medicine, 178(9), 970-973. doi: 10.7205/MILMED-D-13-00080

Coatsworth-Puspoky, R., Forchuk, C., \& Ward-Griffin, C. (2006). Peer support relationships: An unexplored interpersonal process in mental health. Journal of Psychiatric and Mental Health Nursing, 13(5), 490-497. doi: 10.1111/j.1365-2850.2006.00970.x

Cusack, M., \& Montgomery, A. E. (2018). Barriers and facilitators to housing access and maintenance in HUD-VASH: Participant and staff perspectives. Social Work in Health Care, 57(6), 422-439. doi: 10.1080/00981389.2018.1441213

Cyhlarova, E., Crepaz-Keay, D., Reeves, R., Morgan, K., Lemmi, V., \& Knapp, M. (2015). An evaluation of peer-led self-management training for people with severe psychiatric diagnoses. The Journal of Mental Health Training, Education, and Practice, 10(1), 3-13. doi: 10.1108/JMHTEP-08-2014-0020

Dale, A., Arbor, S., \& Procter, M. (1988). Doing secondary analysis. London, UK: Unwin Hyman.

Dandeker, C., Thomas, S., Dolan, M., Chapman, F., \& Ross, J. (2005). Feasibility study on the extent, causes, impact and costs of rough sleeping and homelessness amongst ex service 
personnel in a sample of local authorities in England. London, England: Kings College London, University of London.

Davidson, C., Neighbors, C., Hall, G., Hogue, A., Cho, R., Kutner, B., \& Morgenstern, J. (2014). Association of housing first implementation and key outcomes among homeless persons with problematic substance use. Psychiatric Services, 65(11), 1318-1324. doi: 10.1176/appi.ps.201300195

Draine, J., Salzer, M.S., Culhane, D. P., \& Hadley, T. R. (2002). Role of social disadvantages in crime, joblessness, and homelessness among persons with serious mental illness. Psychiatric Services, 53, 563-573. doi: 10.1176/appi.ps.53.5.565

Dinnen, S., Kane, V., \& Cook, J. (2014). Trauma informed care: A paradigm shift needed for services with homeless veterans. Professional Case Management, 19(4), 161-170. doi: 10.1097/NCM. 0000000000000038

Erickson, P., Butters, J., Walkom K., Butterill, D., Caverson, R., Fischer, B., ... Tupker, E. (2002). CAMH and harm reduction: A background paper on its meaning and application for substance use issues. Retrieved from http://www.camh.ca/en/hospital/about_camh/influencing_public_policy/public_policy_su bmissions/harm_reduction/Pages/harmreductionbackground.aspx

Evans, J., Semogas, D., Smalley, J. G., \& Lohfeld, L. (2015). “This place has given me a reason to care”: Understanding 'managed alcohol programs' as enabling places in Canada. Health \& Place, 33, 118-124. doi: 10.1016/j.healthplace.2015.02.011

Forchuk, C., Nelson, G., \& Hall, B. G. (2006). "It's important to be proud of the place you live in": Housing problems and preferences of psychiatric survivors. Perspectives in Psychiatric Care, 42(1), 42-52. doi: 10.1111/j.1744-6163.2006.00054.x 
Forchuk, C., Reiss, J. P., Mitchell, B., Ewen, S., \& Meier, A. (2015). Homelessness and housing crises among individuals accessing services within a Canadian emergency department. Journal of Psychiatric and Mental Health Nursing, 22, 354-359. doi: 10.1111/jpm.12212

Forchuk, C., Reynolds, W., Sharkey, S., Martin, M. L., \& Jensen, E. (2007). Transitional discharge based on therapeutic relationships: State of the art. Archives of Psychiatric Nursing, 21(2), 80-86. doi: 10.1016/j.apnu.2006.11.002

Forchuk, C., \& Richardson, J. (2015). A Canadian model for housing and support of veterans experiencing homelessness: Housing first practice manual. London, ON: City of London. Retrieved from http://www.homelessprevention.ca

Forchuk, C., Schofield, R., Joplin, L., Csiernik, R., Gorlick, C., \& Turner, K. (2011). Housing, income support, and mental health: Points of disconnection. In C. Forchuk, Csiernik, R., \& Jensen, E. (Eds), Homelessness, Housing, and Mental Health: Finding Truths Creating Change (35-49). Toronto, ON: Canadian Scholars’ Press Inc.

Forchuk, C., Turner, K., Joplin, L., Schofield, R., Csiernik, R., \& Gorlick, C. (2007). Housing, income support and mental health: Points of disconnection. Health Research Policy and Systems, 5(14). doi: 10.1186/1478-4505-5-14

Gaetz, S., Dej, E., Richter, T., \& Redman, M. (2016). The state of homelessness in Canada 2016. Toronto, ON: Canadian Observatory on Homelessness Press. Retrieved from http://homelesshub.ca/sites/default/files/SOHC16_final_20Oct2016.pdf

Gaetz, S., Scott, A., \& Gulliver, T. (2013). Housing first in Canada: Supporting communities to end homelessness. Retrieved from http://www.homelesshub.ca/sites/default/files/HousingFirstInCanada_0.pdf 
Gidugu, V., Rogers, S. E., Harrington, S., Maru, M., Johnson, G., Cohee, J., \& Hinkel, J. (2014). Individual peer support: A qualitative study of mechanisms of its effectiveness. Community Mental Health, 51(4), 445-452. doi: 10.1007/s10597-014-9801-0

Goering, P., Veldhuizen, S., Watson, A., Adair, C., Kopp, B., Latimer, E., ... Aubry, T. (2014). National at Home/Chez Soi Final Project. Calgary, AB: Mental Health Commission of Canada. Retrieved from http://www.mentalhealthcommission.ca/English/system/files/private/document/mhcc_at_ home_report_national_cross-site_eng_2.pdf.

Government of Canada. (2017). Operational stress injury social support (OSISS). Retrieved from https://www.canada.ca/en/department-nationaldefence/services/guide/dcsm/osiss.html

Hardill, K. (2014). Below the radar: An exploration of substance use in rural Ontario. Retrieved from https://canadianharmreduction.com/sites/default/files/Report\%20\%20Below\%20the\%20Radar\%20-\%20Sub\%20Use\%20in\%20Rural\%20Ont\%20\%202011.pdf

Heaton, J. (2004a). Chapter 4: Epistemological issues. The problem of not having 'been there'. In Heaton, J. (Eds), Reworking Qualitative Data (60-65). London, Thousand Oaks, New Delhi: Sage Publications Inc.

Heaton, J. (2004b). Chapter 6: Modi operandi. What is secondary analysis? In Heaton, J. (Eds), Reworking Qualitative Data (89-107). London, Thousand Oaks, New Delhi: Sage Publications Inc.

Heaton, J. (2004c). Chapter 3: Types of qualitative secondary analysis. In Heaton, J. (Eds), Reworking Qualitative Data (35-52). London, Thousand Oaks, New Delhi: Sage 
Publications Inc.

Heaton, J. (2004d). Chapter 1: What is secondary analysis? In Heaton, J. (Eds), Reworking Qualitative Data (1-16). London, Thousand Oaks, New Delhi: Sage Publications Inc.

Hwang, S. W. (2001). Homelessness and health. Canadian Medical Association Journal, 164(2), 229-233.

Johnsen, S. (2013). Turning point Scotland's housing first project evaluation: Final report. Glasgow, Scotland. Turning Point Scotland, Heriot Watt University. Retrieved from http://www.turningpointscotland.com/wp-content/uploads/2014/02/TPS-Housing-FirstFinal-Report.pdf

Johnsen, S., Jones, A., \& Rugg, J. (2008). The experience of homeless ex-service personnel in London: Research report. York, United Kingdom: Centre for Housing Policy, The University of York. Retrieved from https://www.york.ac.uk/media/chp/documents/2008/HomelessExServiceinLondon.pdf

Kidd, S. A., Virdee, G., Mihalakakos, G., McKinney, C., \& Feingold, L. Collins, A., ... Velligan, D. (2016). The welcome basket revisited: Testing the feasibility of a brief peer support intervention to facilitate transition from hospital to community. Psychiatric Rehabilitation Journal, 39(4), 335. doi: 10.1037/prj0000235

Krause, D., Serge, L., \& Goldberg, M. (2005). Homelessness, housing, and harm reduction: stable housing for homeless people with substance use issues. Retrieved from http://www.cmhc-schl.gc.ca/odpub/pdf/65088.pdf?fr = 1447873995478 .

Krusi, A., Fast, D., Small, E., Wood, E., \& Kerr, T. (2010). Social and structural barriers to housing among street-involved youth who use illicit drugs. Health \& Social Care in the Community, 18(3), 282-288. doi: 10.1111/j.1365-2524.2009.00901.x 
Lawn, S., Smith, A., \& Hunter, K. (2009). Mental health peer support for hospital avoidance and early discharge: An Australian example of consumer driven and operated service. Journal of Mental Health, 17(5), 498-508. doi: 10.1080/09638230701530242

Lee, J. E. C., \& Hachey, K. K. (2011). Descriptive analyses of the Recruit Health Questionnaire: 2007-2009 (DGMPRA TM 2011-028). Ottawa, Ontario: Director General Military Personnel Research and Analysis, Department of National Defence.

MacLean, M.B., VanTil, L., Kriger, D., Sweet, J., Poirier, A., \& Pedlar, D. (2013). Well-being of Canadian Forces veterans: Canadian community health survey 2003. Charlottetown, P.E.I: Veterans Affairs Canada, Research Directorate.

MacNeil, J., \& Pauly, B. M. (2010). Needle exchange as a safe haven in an unsafe world. Drug \& Alcohol Review, 30(1), 26-32. doi: 10.1111/j.1465-3362.2010.00188.x

McLean, J., Woodhouse, A., Biggs, H., \& Bowie, J. (2012). Exploring peer support as an approach to supporting self management. Edinburgh, Scotoland: Mental Health Foundation. Retrieved from https://www.mentalhealth.org.uk/sites/default/files/ exploring_peer_support.pdf

Milroy, W. H. (2009). From welfare to well-being: Turning things around among homeless veterans In J.A. Mancini \& K. A. Roberto (Eds). Pathways of Human Development: Explorations of Change, (pp. 327-346). Maryland: Lexington Books.

Milroy, W. H. (2001). Pathways to the streets for ex-service personnel: An examination of various routes to homelessness for ex-service personnel (Doctoral dissertation). University of East Anglia, Norwich, United Kingdom. 
Molinari, V. A., Brown, L. M., Frahm, K. A., Schinka, J. A., \& Casey, R. (2013). Perceptions of homelessness in older homeless veterans, a VA homeless program staff liasons, and housing intervention providers. Journal of Health Care for the Poor and Underserved, 24(2), 487-498. doi: 10.1353/hpu.2013.089

Montgomery, A. E., Hill, L. L., Kane, V., \& Culhane, D. P. (2013). Housing chronically homeless veterans: Evaluating the efficacy of a housing first approach to HUD-VASH. Journal of Community Psychology, 41(4), 505-514. doi: 10.1002/jcop.21554

Nolan, S., Hyashi, K., Milloy, M., Kerr, T., Dong, H., Lima, D., . . Wood, E. (2015). The impact of low-threshold methadone maintenance treatment on mortality in a Canadian setting. Drug Alcohol Depend, 1, 57-61. doi: 10.1016/j.drugalcdep.2015.08.037

O’Connell, M. J., Kasprow, W. J., \& Rosenheck, R. A. (2016). Impact of supported housing on social relationships among homeless veterans. Psychiatric Services, 68(2), 203-206. doi: 10.1176/appi.ps.201500276

Orenelas, J. (2013). Casas Primerio, Lisboa. Final report for housing first Europe. Lisbon, Portugal.

Pauly, B., Gray, E., Perkin, K., Chow, C., Vallace, K., Krysowaty, B., \& Stockwell, T. (2016). Finding safety: A pilot study of managed alcohol programs participants' perceptions of housing and quality of life. Harm Reduction Journal, 13(15), 1-11. doi: 10.1186/s12954016-0102-5

Pauly, B., Reist, D., Belle-Isle, L., \& Schactman, C. (2013). Housing and harm reduction: What is the role of harm reduction in addressing homelessness? International Journal of Drug Policy, 24, 284-290. doi: 10.1016/j.drugpo.2013.03.008 
Petrar, S., Kerr, T., Tyndall, M. W., Zhang, R., Montaner, J., \& Wood, E. (2007). Injection drug users' perceptions regarding use of medically supervised safer injecting facility. Addictive Behaviours, 32(5), 1088-1093. doi: 10.1017/j.addbed.2006.07.013

Piat, M., Lesage, A., Boyer, R., Dorvil, H., Couture, A., Grenier, G., \& Bloom, D. (2008). Housing for persons with serious mental illness: Consumer and service provider preferences. Psychiatric Services, 59(9), 1011-1017. doi: 10.1176/appi.ps.59.9.1011

Please, N., \& Quilgars, D. (2013). Improving health and social integration through housing first: A review. York, United Kingdom: Centre for Housing Policy, University of York. Retrieved from https://www.york.ac.uk/media/chp/documents/2013/improving_ health_and_social_integration_through_housing_first_a_review.pdf

Podymow, T., Turnbull, J., Coyle, D., Yetisir, E., \& Wells, G. (2006). Shelter based managed alcohol administration to chronically homeless people addicted to alcohol. Canadian Medical Association Journal, 174(1), 45-49. doi: 10.1503/cmaj.1041350

Public Health Agency of Canada. (2006). The human face of mental health and mental illness in Canada 2006. Ottawa, ON: Minister of Public Works and Government Services Canada.

Ray, S. L., \& Forchuk, C. (2011). Experience of homelessness among Canadian Forces and allied forces Veterans (Research Report submitted to HRSDC Canada). Retrieved from http://www. homelesshub.ca/sites/default/ les/Homelesss\%20Vets\%20Article.pdf

Resnick, L., Ekerholm, S., Johnson, E. E., Ellison, M. L., \& O’Toole, T. P. (2017). Which homeless veterans benefit from a peer mentor and how? Journal of Clinical Psychology, 73(9), 1027-1047. doi: 10.1002/jclp.22407 
Resnick, S. G. \& Rosenheck, R. A. (2008). Integrating peer-provided services: A quasiexperimental study of recovery orientation, confidence, and empowerment. Psychiatric Services, 59(11), 1307-1314. Retrieved from http://ps.psychiatryonline.org/loi/ps

Richer, I., Lee, J., \& Born, J. (2016). Patterns of alcohol use among Canadian military personnel and their associations with health and well-being. Health Psychology, 35(7), 685-694. doi: $10.1037 /$ hea0000328

Schutt, R. K., Weinstein, B., \& Penk, W. E. (2005). Housing preferences of homeless veterans with dual diagnoses. Psychiatric Services, 56(3), 350-352. doi: 10.1176/appi.ps.56.350

Segaert, A., \& Bauer, A. (2015). The extent and nature of veteran homelessness in Canada. Retrieved from https://www.canada.ca/en/employment-socialdevelopment/programs/communities/homelessness/publications-bulletins/veteransreport.html

Somers, J. M., Moniruzzaman, A., \& Palepu, A. (2015). Changes in daily substance use among people experiencing homelessness and mental illness: 24-month outcomes following randomization to Housing First or usual care. Addiction, 110, 1605-1614. doi:

10.1111/add.13011

Strebnik, D., Livingston, J., Gordon, L., \& King, D. (1995). Housing choice and community success for individuals with serious and persistent mental illness. Community Mental Health Journal, 31(2), 139-152. Retrieved from https://link.springer.com/journal/10597

Szabo, V., \& Strang, V. R. (1997). Secondary analysis of qualitative data. Advances in Nursing Science, 20(2), 66-74. doi: 00012272-199712000-00008

Thomas, G. (2005) Harm Reduction Policies and Programs Involved for Persons Involved in the Criminal Justice System. Ottawa: Canadian Centre on Substance Use. 
Travis, J., Roeder, K., Walters, H., Piette, J., Heisler, M., Ganoczy, D., ...Pfeiffer, P. (2010). Telephone-based mutual peer support for depression: A pilot study. Chronic Illness, 6(3), 183-191. doi: $10.1177 / 1742395310369570$

Tsai, J., Bond, G. R., Salyers, M. P., Godfrey, M. P., \& Davis, K. E. (2010). Housing preferences and choices among adults with mental illness and substance use disorders: A qualitative study. Community Mental Health Journal, 46(4), 381-388. doi: 10.1007/s1059-009-92686

Tsai, J., Ramaswamy, S., Bhatia, S. C., \& Rosenheck, R. A. (2015). A comparison of homeless male veterans in metropolitan and micropolitan areas in Nebraska: A methodological caveat. American Journal of Community Psychology, 56(3-4), 357-367. doi: 10.1007/s 10464-015-9746-7.

Tsai, J., \& Rosenheck, R. A. (2012). Outcome of a group of intensive peer-support model of case management for supported housing. Psychiatric Services, 63(12), 1186-1194. doi: 10.1176/appi.ps.201200100

U.S. Department of Housing and Urban Development. (2011). The applicability of housing fist models to homeless persons with serious mental illness: Final report. Washington, D.C., U.S.A: Author. Retrieved from https://www.huduser.gov/portal/publications/hsgfirst.pdf Vallance, K., Stockwell, T., Pauly, B., Chow, C., Gray, E., Krysowaty, B., ... \& Zhao, J. (2016). Do managed alcohol programs change patters of alcohol consumption and reduce related harm? A pilot study. Harm Reduction Journal, 13(13), 10.1186/s12954-016-0103-4

Warren, R., \& Bell, P. (2008). An exploratory investigation into the housing preferences of consumers of mental health services. International Journal of Mental Health Nursing, 9(4), 195-202. doi: 10.1046/j.1440-0979.2000.00172.x 
Weber, S. J. (1986). The nature of interviewing. Phenomenology + Pedagogy, 4(2), 65-72.

Werb, D., Wood, E., Small, W., Strathdee, S., Li, K., Montaner, J., \& Kerr, T. (2008). Effects of police confiscation of illicit drugs and syringes among injection drug users in Vancouver. International Journal on Drug Policy, 19, 332 338. doi:10.1016/j.drugpo.2007.08.00

Wewerinke, D., al Shamma, S., \& Wolf, J. (2013). Housing first Europe location evaluation report Amsterdam. Nijmegen, The Netherlands: Netherlands Centre for Social Care research. Retrieved from http://housingfirstguide.eu/website/wpcontent/uploads/2016/03/Amsterdam_HFE_Local_Evaluation.pdf

Whitehead, J., \& Hawes, R. A. (2010). Canadian Forces health and lifestyle information survey 2008/09 Regular Force report. Ottawa, Ontario, Canada: Canadian Forces Health Services Group, Department of National Defence.

Young, M. G., \& Manion, K. (2017). Harm reduction through housing first: An assessment of the emergency warming center in Inuvik, Canada. Harm Reduction Journal, 14(8), 1-11. doi: 1 0.1186/s12954-016-0128-8 


\section{CHAPTER III}

\section{IMPLICATIONS FOR NURSING}

The purpose of this secondary analysis was to explore harm reduction among Canadian Armed Forces (CAF) veterans experiencing homelessness. Particularly, this study sought to uncover CAF veterans' experiences with harm reduction and reveal what this approach means to them. A thematic analysis was conducted on veteran focus group data from The Canadian Model for Housing and Support of Veterans Experiencing Homelessness study, which evaluated a veteran-specific housing strategy in Victoria, Toronto, Calgary, and London (Forchuk \& Richardson, 2015). The experiences the veterans shared during the focus groups demonstrated that they are a unique homeless population with specific health, housing, and addiction needs.

Analysis of focus group data revealed several themes that captured the veterans' understanding of harm reduction: (a) Regimented Structure, (b) Understanding Both Worlds, (c) Congruent Recovery Journeys, (d) Location: Close Enough to Services, Far Enough from Harm, and (e) Harm Reduction is Housing Stability and Housing Stability is Harm Reduction. These themes have shown that veterans' perceptions of harm reduction are strongly influenced by their military background. The findings also emphasized their strong desire to re-connect with military culture and to access housing that implements harm reduction. This study may have many implications for policy, Housing First programs, nursing practice, nursing education, and nursing research.

\section{Implications for Policy}

According to the World Health Organization (2013), policy at all levels influences the conditions and environments in which people live, work, and grow. The inequitable distribution of society's resources due to historic policy decisions has negatively impacted the lives of those 
living with mental illness and homelessness. Specifically, the lack of national policies for housing, income support, and mental health is largely responsible for the current state of mass homelessness in Canada (Forchuk et al., 2011). Until recently, Canada was one of the only industrialized countries without a national housing strategy (Homeless Hub, 2017).

In November 2017, the federal government invested $\$ 40$ billion into the National Housing Strategy (NHS) to increase access to safe and affordable housing in Canada. This strategy acknowledges and prioritizes the needs of key homeless populations, including youths, women, Indigenous peoples, and veterans (The Government of Canada, 2017). Although this strategy represents an important step in addressing veteran homelessness, it has received criticism from the public and veteran organizations. Specifically, it remains unclear as to how exactly this strategy will address veteran homelessness. Therefore, critics have argued that a national veteran-specific housing strategy is needed (Berthiaume, 2017). Alternatively, the current NHS could be expanded to include specific funding, policies, and strategies to address homelessness among veterans, rather than simply listing them with other key groups as a priority population. A housing strategy that acknowledges the needs of veterans may effectively address homelessness among this group. Preventing and addressing homelessness requires an understanding of the needs of key homeless groups, including veterans (Gaetz, Dej, Richter, \& Redman, 2016). Housing policies at all levels must recognize these unique needs, since there is no one-size-fits-all solution to homelessness (Gaetz et al., 2016). It is suggested that exploring the lived experiences of individuals may reveal both the causes and solutions to homelessness (Hulchanski, Campsie, Chau, Hwang, \& Paradis, 2009). Therefore, understanding veterans’ perceptions of harm reduction may reveal the policy solutions to homelessness and substance use among this group. 
The findings of this study may have several implications for the development of policy to prevent and address homelessness among CAF veterans. During focus group discussions, veterans often spoke of the high use and availability of alcohol in the military. For many of them, their alcohol-consumption during service contributed to the substance use issues they experienced after exiting the military. Previous Canadian research has also revealed that substances, particularly alcohol, are used by some veterans to cope with their difficult transition from military to civilian life. Ultimately, this problematic substance use may contribute to homelessness many years after military service (Ray \& Forchuk, 2011; Forchuk \& Richardson, 2015). Currently, there are several initiatives and programs that Veterans Affairs Canada (VAC), the Department of National Defence, and the CAF are instituting to address alcohol misuse within the military. For example, National Defence's (2018) Strengthening the Forces health promotion program teaches $\mathrm{CAF}$ members how to prevent or cope with an addiction. Despite the implementation of these various programs, alcohol use within the military remains an issue (Lee \& Hachey, 2011; Richer, Lee, \& Born, 2016). This study has provided impetus for increased programming and support services for CAF members experiencing substance use issues. Additional support for these individuals during service and throughout their transition to civilian life may prevent the "downward spiral” (p. 11) into homelessness (Ray \& Forchuk, 2011). Given that alcoholism is a major contributing factor to veteran homelessness (Ray \& Forchuk, 2011; Forchuk \& Richardson, 2015), housing policies that include harm reduction may be needed.

Housing policy can be defined as the "actions of government, including legislation, and program delivery, which have a direct or indirect impact on housing supply and availability, housing standards, and urban planning” (Homeless Hub, 2017). While housing has been acknowledged as a human right in the NHS (The Government of Canada, 2017), it has not been 
formally written into rights legislation including Canadian Charter of Rights and Freedoms or the Constitution Act of 1982 (Heffernan, Faraday, \& Rosenthal, 2015). Consequently, limited access to affordable housing remains an issue for many homeless groups, including veterans (Gaetz et al., 2016). However, this study may have many implications for the development of rights-based housing policies to address homelessness among CAF veterans. The findings revealed that veterans require structured housing that not only fulfills their need to re-connect with the military culture, but also implements a harm reduction approach.

The release of the country's first NHS represents an important step in addressing homelessness among key populations, including veterans (The Government of Canada, 2017). However, further steps must be taken to develop a veteran-specific national housing policy or refine the current NHS to incorporate specific actions to address veteran homelessness. Exploring harm reduction among veterans experiencing homelessness has shown that they are unlike any other homeless group and have unique housing and health needs. Housing policies that consider these needs and incorporate harm reduction may ultimately reduce the occurrences of veteran homelessness.

\section{Implications for Housing First Programs}

The findings of this study may also inform the development of future veteran-specific Housing First programs. The veterans often spoke of the necessity of implementing harm reduction to facilitate stable housing. They described how this approach got them into a stable and safe living environment where they could address their substance use issues. Furthermore, the veterans required structured housing which reflected the regimented nature of the military, including the presence of rules. However, Housing First programs may need to explore how this structure can be incorporated for veterans without violating the principles of harm reduction. 
Many of the veterans also reported that they were incompatible with some housing and support workers, as they were often young and did not possess a military background. Therefore, the veterans recommended that housing programs hire staff who are older in age and understand the military culture. However, employing individuals based on age is incongruent with Ontario labor laws (Ontario Human Rights Commission, 2012). Alternatively, programs may provide staff with veteran-specific training or advertise in job postings a preference for candidates who have prior experience working with veterans. The location of housing was also integral to the veterans' recovery from homelessness and substance use. They often recommended that housing have a central location that is close enough to essential services, but far enough away from the substance-related harms associated with the downtown cores of cities. Overall, these findings can inform how Housing First programs address the unique needs and preferences of veterans.

\section{Implications for Nursing Practice}

Nurses in all health care settings provide care to individuals experiencing homelessness and substance use issues. Under the Canadian Nurses Association's (CNA) Code of Ethics for Registered Nurses, nurses are ethically-bound to provide compassionate care to individuals regardless of their age, gender, socioeconomic status, religion, and lifestyle choices (CNA, 2017). The philosophy of harm reduction is consistent with the ethical standards of the nursing profession, since it promotes autonomy, human dignity, compassion, and empowerment (CNA, 2018; Pauly, Gagnon, Goldstone, \& Christie, 2017). Therefore, nurses are very well-suited to deliver harm reduction services. This study may have many implications for nursing practice and the care that is provided to veterans.

In Canada, the exact number of veterans experiencing homelessness is currently unknown (Gaetz et al., 2016). It is difficult to identify these individuals, since they are more likely to be 
living "in the rough" and outside of shelters (Segaert \& Bauer, 2015). However, nurses may be in a unique position to identify veterans experiencing homelessness given their close relationships and contact with clients. During assessments, nurses can inquire if a client has served in the military and if he or she identifies as a veteran. Furthermore, they can screen for housing issues and substance use and, if necessary, co-ordinate the appropriate harm reduction resources and supports. Identifying veterans who are homeless, or at risk of becoming so, may further reveal the nature and extent of veteran homelessness in Canada.

The findings of this study may be also used to inform nursing care that congruent with the needs of veterans. Ray (2009) explains that Canadian nurses are increasingly caring for exmilitary members in a variety of settings, such as OSI clinics. To provide effective care, nurses must understand veterans' needs and how to adequately address them. During the focus groups, some of the veterans reported that support staff were occasionally inaccessible and difficult to connect with. Often, they had trouble trying to navigate the system and the various resources that were available to them. Nurses can work with veterans to "cut through the red tape" and coordinate the resources and services they need. Adhering to a structured schedule was also important for veterans, which often originated from their strict military background. Therefore, nurses need to respect and honor previously agreed upon appointments and meetings. Furthermore, nurses may be in an ideal position to teach veterans about a harm reduction approach in general and resolve the misconceptions they may hold. Overall, recognizing these needs may facilitate greater therapeutic relationships between nurses and veterans.

Various organizations and agencies were involved in the veteran-specific housing programs. Depending on the housing site, the veterans received support from VAC, OSI clinics, the Royal Canadian Legion, veteran volunteers, and local police associations (Forchuk \& 
Richardson, 2015). For many of the veterans, interacting with these organizations was an essential component of their recovery. Given the complex nature of homelessness, addressing this issue may require collaboration among various groups and organizations (Schiff \& Waegemakers Schiff, 2016; CNA, 2017). Therefore, nurses can work with these numerous groups and agencies to ensure a more collaborative and co-ordinated response to veteran homelessness.

Advocating for ethical social and health policies is an essential component of nursing practice. According to The Code of Ethics for Registered Nurses, nurses are obligated to challenge unjust policies that negatively impact the health and well-being of vulnerable groups (CNA, 2017). In Canada, most nurses may be unaware of the extent of veteran homelessness since very little is known about this issue (Ray \& Forchuk, 2011). However, nurses must acknowledge that veteran homelessness exists in order to advocate for the appropriate solutions, including harm reduction. Nursing in all settings should support harm reduction, as it aligns with nursing professional and ethical standards (CNA, 2018; Pauly et al., 2017). Advocating for this approach may increase public awareness and eliminate the controversy and misconceptions surrounding it. Addressing veteran homelessness may also require a participatory approach, whereby nurses collaborate directly with veterans. Actively participating in the political process may empower these veterans to gain control over their lives and situations (Tengland, 2012; Rootman \& O’Neil, 2012).

\section{Implications for Nursing Education}

Nursing education must emphasize the root causes of veteran homelessness in Canada, including the lack of national policies for housing and mental health (Draine, Salzer, Culhane, \& Hadley, 2002; Forchuk et al., 2011). Curricula should highlight the principle of social justice, 
particularly the nurse's role in advocating for change. Nursing students must recognize that they are ethically obligated to challenge policies and practices that negatively impact the health and well-being of clients, families, and communities (CNA, 2017). Furthermore, students should be taught their role in delivering evidence-based interventions, including harm reduction.

The study findings have shown that harm reduction was essential for the veterans during their recovery. Nursing students should be educated about harm reduction, since this approach is congruent with nursing practice standards (CNA, 2018; Pauly et al., 2017). They will likely care for individuals and families affected by substance use, so it is imperative that they understand and incorporate this approach into their practice. Understanding the principles of harm reduction may allow these students to provide care that maintains the safety and dignity of clients, including veterans.

Exploring the lived experiences and needs of homeless veterans should be incorporated into nursing education. The study findings revealed that veterans preferred interacting with support staff who understood the military culture and language. Some of the veterans were unable to relate to who was helping them, which resulted in conflict and ineffective relationships with staff. Therefore, nursing curricula could provide students with a basic understanding of the military culture. Understanding this unique culture may prepare nursing students to provide culturally competent care that is consistent with the needs and values of veterans. Education on other key veteran groups, such as women and the Indigenous people, may also be needed.

\section{Implications for Nursing Research}

This study has contributed to the little knowledge that exists on veteran homelessness in Canada. However, further research is needed, supplementing findings from other countries which cannot be directly applied to the Canadian context. Particularly, research exploring the lived 
experiences of veterans may uncover the solutions to homelessness among this group (Hulchanski et al., 2009). The study findings revealed that harm reduction assisted the veterans in their recovery from homelessness and substance use. Therefore, additional research exploring how this group experiences harm reduction may further support its use in addressing veteran homelessness. Future research can also reveal effective models of veteran-specific housing that balance the flexibility of harm reduction with the structure often sought by veterans. Future research, however, should be conducted as a participatory process with veterans.

Participatory action research (PAR) requires the involvement of participants and community partners in the development, implementation, and evaluation of a study. As Berman, Ford-Gilboe, and Campbell (1998, p. 13) explain, "Bringing about change necessitates active involvement of those toward whom change is directed." PAR research is distinct from other types of research, as it is action-oriented and aims to empower those who are involved (Baum, MacDougall, \& Smith, 2006). Therefore, nursing researchers can partner with veterans to address the inequities that have contributed to their homelessness and substance use. Participating directly in research initiatives may provide veterans the opportunity to reflect on their situations and gain power over their lives.

Most of the participants who enrolled in the primary study were male (92\%) and white English Canadians (79\%). Of the total sample, $8 \%$ were female and only $9.7 \%$ identified as Aboriginal or Metis (Forchuk \& Richardson, 2015). Consequently, the stories that were shared during focus groups may not have represented the experiences of women, Indigenous, or Metis veterans. Additional research may be needed to explore these groups' experiences with harm reduction. Understanding these experiences may facilitate a more specific and targeted response to veteran homelessness. 


\section{Conclusion}

This study has shown that veterans require housing and supports that incorporate the harm reduction philosophy. Furthermore, their understanding of this approach is strongly influenced by their military background and culture. These findings may be used to inform the development of policies, such as a veteran-specific housing strategy, to adequately address veteran homelessness. With respect to nursing practice, these findings may also influence how nurses care for veterans experiencing homelessness. Understanding the experiences of veterans will enable nurses and students to provide care that is tailored to this group's unique needs. These findings also support additional Canadian research that explores harm reduction among veterans, including females and the Indigenous people. Involving veterans directly in the research process may be key to addressing homelessness and substance use among this group. Ultimately, veterans may become empowered to challenge and address the inequities that have historically limited their access to safe and affordable housing. 


\section{References}

Baum, F., MacDougall, C., \& Smith, D. (2006). Participatory action research. Journal of Epidemiology and Community Health, 60(10), 854-857. doi: 10.1136/jech.2004.028662

Berman, H., Ford-Gilboe, M., Campbell, J. C. (1998). Combining stories and numbers: A methodologic approach for a critical nursing science. Advances in Nursing Science, 21(1), 1-15. Retrieved from https://journals.lww.com/advancesinnursingscience/pages/default .aspx

Berthiaume, J.. (2017, November 24). Federal housing plan too vague on help for homeless veterans, says critics. The Canadian Press. Retrieved from http://www.macleans.ca/politi cs/federal-housing-plan-too-vague-on-help-for-homeless-veterans-say-critics/

Canadian Nurses Association. (2017). Code of ethics for registered nurses. Ottawa, ON: Author. Retrieved from https://www.cna-aiic.ca/ /media/cna/page-content/pdf-en/code-of-ethics2017-edition-secure-interactive

Canadian Nurses Association. (2018). Joint position statement: Harm reduction and substance use. Ottawa, ON: Author. Retrieved from https://www.cna-aiic.ca/-/media/cna/pagecontent/pdf-en/joint_position_statement_harm_reduction_and_substance_use.pdf

Draine, J., Salzer, M.S., Culhane, D. P., \& Hadley, T. R. (2002). Role of social disadvantages in crime, joblessness, and homelessness among persons with serious mental illness. Psychiatric Services, 53, 563-573. doi: 10.1176/appi.ps.53.5.565

Forchuk, C., \& Richardson, J. (2015). A Canadian model for housing and support of veterans experiencing homelessness: Housing first practice manual. London, ON: City of London. Retrieved from http://www.homelessprevention.ca

Forchuk, C., Schofield, R., Joplin, L., Csiernik, R., Gorlick, C., \& Turner, K. (2011). Housing, 
income support, and mental health: Points of disconnection. In C. Forchuk, Csiernik, R., \& Jensen, E. (Eds), Homelessness, Housing, and Mental Health: Finding Truths Creating Change (35-49). Toronto, ON: Canadian Scholars’ Press Inc.

Homeless Hub. (2017). Housing policy. Retrieved from http://homelesshub.ca/solutions/afford able-housing/housing-policy

Hulchanski, J. D., Campsie, P., Chau, S. B. Y., Hwang, S. W., \& Paradis, E. (2009). Homelessness: What's in a word? In Hulchanski, J. D., Campsie, P., Chau, S. B. Y., Hwang, S. W., \& Paradis, E. (Eds.). Finding Home: Policy Options for Addressing Homelessness in Canada (e-book). Toronto, ON: Cities Centre, University of Toronto.

Gaetz, S., Dej, E., Richter, T., \& Redman, M. (2016). The state of homelessness in Canada 2016. Toronto, ON: Canadian Observatory on Homelessness Press. Retrieved from http://homelesshub.ca/sites/default/files/SOHC16_final_20Oct2016.pdf

The Government of Canada. (2017). Canada's national housing strategy. Ottawa, ON: Author. Retrieved from https://www.placetocallhome.ca/pdfs/Canada-National-HousingStrategy.pdf

Heffernan, T., Faraday, F., \& Rosenthal, P. (2015). Fighting for the right to housing in Canada. Journal of Law and Social Policy, 24. 10-45. Retrieved from http://digitalcommons.osgo ode.yorku.ca/jlsp/vol24/iss1/2

Lee, J. E. C., \& Hachey, K. K. (2011). Descriptive analyses of the Recruit Health Questionnaire: 2007-2009 (DGMPRA TM 2011-028). Ottawa, Ontario: Director General Military Personnel Research and Analysis, Department of National Defence. 
National Defence. (2018). Strengthening the forces health promotion program. Retrieved from https://www.canada.ca/en/department-national-defence/programs/strengtheningforces.html

Ontario Human Rights Commission. (2012). Age Discrimination. Retrieved from http://www.ohrc.on.ca/en/age-discrimination-brochure

Pauly, B., Gagnon, M., Goldstone, I., \& Christie, T. (2017). Harm reduction \& illicit substance use: Implications for nursing. Ottawa, ON: Canadian Nurses Association. Retrieved from https://www.cna-aiic.ca/-/media/cna/page-content/pdf-en/harm-reduction-and-illicitsubstance-use-implications-fornursing.pdf?la=en\&hash=5F5BBCDE16C7892D9C7838CF62C362685CC2DDA7

Ray, S. (2009). Contemporary treatments for psychological trauma from the perspectives of peacekeepers. The Canadian Journal of Nursing Research, 41(2), 115-128. Retrieved from http://journals.sagepub.com/home/CJN

Ray, S. L., \& Forchuk, C. (2011). Experience of homelessness among Canadian Forces and allied forces Veterans (Research Report submitted to HRSDC Canada). Retrieved from http://www. homelesshub.ca/sites/default/ les/Homelesss\%20Vets\%20Article.pdf

Richer, I., Lee, J., \& Born, J. (2016). Patterns of alcohol use among Canadian military personnel and their associations with health and well-being. Health Psychology, 35(7), 685-694. doi: $10.1037 /$ hea0000328

Rootman, I., \& O’Niell, M. (2012). Key concepts in health promotion. In Rootman, I., Dupere, S., Pederson, A., \& O’Niell. (3 ${ }^{\text {rd }}$ Eds), Health Promotion in Canada: Critical Perspectives on Practice (18-32). Toronto, ON: Canadian Scholars’ Press Inc. 
Schiff, R., \& Waegemakers-Schiff, J. (2016). Collaborative approaches to addressing homelessness in Canada: Value and challenge in the community advisory board. Toronto, ON: Canadian Observatory on Homelessness. Retrieved from http://homelesshub.ca/sites/default/files/3.5\%20Schiff\%20Schiff_1.pdf

Segaert, A., \& Bauer, A. (2015). The extent and nature of veteran homelessness in Canada. Retrieved from https://www.canada.ca/en/employment-socialdevelopment/programs/communities/homelessness/publications-bulletins/veteransreport.html

Tengland, P. (2012). Behavior change or empowerment: On the ethics of health promotion strategies. Public Health Ethics, 5(2), 140-153. doi: 10.1093/phe/phs022

World Health Organization. (2013). Social determinants of health. Retrieved from http://www.who.int/topics/social_determinants/en 


\author{
Appendix A \\ National Veteran Project: Veteran Group \\ Letter of Information
}




\section{Letter of Information and Consent \\ (for potential Veteran participants in focus groups) \\ National Veterans Project}

You are being invited to participate in a study to evaluate the impact of housing and related supports in the Veteran population. The purpose of the study is to evaluate a multi-site project that aims to provide Canadian Veterans with a history (or risk) of homelessness with access to affordable, stable, transitional or permanent accommodation in Victoria, Calgary, Toronto and London, Canada. The evaluation component of this project will be conducted by a team of researchers from the Lawson Health Research Institute and the University of Western Ontario. As a Veteran, we would like to hear your personal experiences related to your housing situation and any related supports you have received. The purpose of this letter is to provide you with information to make an informed decision on participating in this research. In other words, this letter contains information to help you decide whether or not to participate in this study. Please take the time to read this carefully. Feel free to ask questions if anything is unclear or if there are words or phrases that you do not understand. This letter is yours to keep.

\section{Description of Project}

This study is about evaluating a multi-site project that provides housing and related supports to Canadian Veterans who have been homeless or who have been at risk of homelessness. Specifically, we will focus on identifying process issues and outcomes achieved through implementation of housing and other related supports with an overall goal to improve the lives of Canadian Veterans and to prevent and/or minimize the risk of homelessness in this population. Up to 132 Veterans over two years will participate in this study and this focus group will take approximately 1- 2 hours to complete.

\section{Procedure}

In this study, you will participate in a focus group; a focus group is a group of people who discuss an issue of common interest to them, with the help of one or more persons who facilitate the group discussion. The focus group will take place at a convenient community agency arranged with the researchers. This focus group will ask questions about your feelings and experiences related to homelessness, housing and related supports as well as details specifically regarding the pilot housing project site from which you are receiving service and support (Victoria, Calgary, Toronto or London). Focus group members are asked to keep everything they hear confidential and not to discuss it outside of the meeting. However, we cannot guarantee that group members will maintain confidentiality. The focus group will take between 1-2 hours. All focus groups will be audio recorded and transcribed for analysis, and will be facilitated by the investigator or her research team. As a thank you for your participation, lunch or refreshments will be provided at the meeting and you will be given $\$ 20$.

If you are participating in another study at this time, please inform the investigator right away to determine if it is appropriate for you to participate in our research.

\section{Risks}

There are no known risks for participating in this study. 


\section{Benefits}

Participants in this study may benefit from having an opportunity to voice their concerns and to participate in a study that may prove to have a real, concrete effect on how programs and services are developed to assist Veterans in accessing housing and related supports.

\section{Confidentiality}

Your part in this study is completely confidential. No information that discloses your identity will be released or published. The audio recordings will only be accessed or heard by the investigators and their research team. Digital recordings will be stored electronically on password protected computers at London Health Sciences Centre - South Street Campus. The recordings will be destroyed after the study is completed. The transcriptions and the other information collected about you will not have your personal identifying details and will be kept under lock and key and on a computer with a protected password at London Health Sciences Centre - South Street Campus. Information from these focus groups will be used within this multi-site project to improve or modify services at each of the four project sites (Victoria, Calgary, Toronto, and London) based on feedback from participants. The master list will be destroyed at the end of the data collection. However, data with no identifying information will be retained for further analysis in the future. If you would like to receive a copy of the overall results of this study, please put your name on a blank piece of paper and give it to the investigator interviewing you.

Representatives of The University of Western Ontario Health Sciences Research Ethics Board may contact you or require access to your study-related records to monitor the conduct of the research.

\section{Voluntary Participation}

Participation in this study is voluntary. You may refuse to participate, refuse to answer any questions or withdraw from the study at any time with no effect on your future care. You do not waive any legal rights by signing the consent form.

If you have any questions you may direct them to the principal investigator or to the chief administration officer.

If you have any questions about the conduct of this study or your rights as a research subject, you may contact (name). 


\section{National Veterans Project \\ (Veteran Participants) \\ Consent Form}

I have read the Letter of Information, have had the nature of the study explained to me, and I agree to participate. All questions have been answered to my satisfaction.

Name (Print):

Signature:

Date:

, 20

Name of Person Responsible for Obtaining Informed Consent (Print):

Signature of Person Responsible for Obtaining Informed Consent:

Date: , 20 
Appendix B

National Veteran Project: Veteran Group

Focus Group Invitation 


\section{"HOLD the DATE" \\ NATIONAL VETERANS PROJECT - FOCUS GROUP DISCUSSION}

Please join us to participate in a focus group discussion to assist in the evaluation of the "National Veterans Project". This multi-site pilot project aims to provide Canadian Veterans with a history (or risk) of homelessness with access to affordable, stable housing with support in Victoria, Calgary, Toronto and London, Canada. We would like to hear your perspective on the housing, supports and related services that are currently offered as a part of this project, including the strengths and challenges that you see as apparent. Focus groups will be facilitated by Dr. Cheryl Forchuk from Lawson Health Research Institute in London, ON. Additional information is included in the attached Letter of Information.

Place: (insert site specific location, directions here)

Date: (insert date)

Time: (insert time)

Thank you for your interest and involvement in the study. For more information please contact (insert local name and phone of staff). Please RSVP by (insert date). 
Appendix C

National Veteran Project: Veteran Group

Semi-structured Interview Guide for Focus Groups 


\section{Veteran Focus Group Interview Guide}

1. Tell us about your current housing situation and the types of supports you receive.

2. What aspects of the housing program and supports that you are receiving have been helpful? What is working well?

3. What aspects of the program could be improved? Specific suggestions?

4. If it were up to you, how would you plan services for you and people in your situation?

\section{Additional Questions:}

- What Veteran serving organizations have you worked with in the project?

- What have been the benefits of working with Veteran serving organizations?

- What have been the challenges of working with the Veteran serving organizations?

- What non-veteran organizations do you work with to support the Veterans in the project?

- What have been the benefits of working with non-Veteran organizations?

- What have been the challenges of working with non-Veteran organizations?

- How has a Housing First philosophy and intervention assisted housing in achieving housing stability?

- $\quad$ How has providing the service separate from the general homeless population helped in delivery housing stability?

- How have you applied a harm reduction approach to address addiction? 


\section{Curriculum Vitae}

Name:

Education:

Honors and Awards:

Professional Associations:

Employment:
Olivia Anne Marsella

The University of Western Ontario

London, Ontario

2016 - 2018 Master of Science in Nursing (MScN)

The University of Western Ontario

London, Ontario

2012 - 2016 Bachelor of Science in Nursing (BScN)

The Western Scholarship of Excellence

2012

Dean's Honor List

$2012-2013$

NOVA Chemicals Higher Education Award

$2012-2016$

Member, Registered Nurses' Association of Ontario (RNAO) 2018

Member, Mental Health Nursing Interest Group (RNAO) 2018

Member, Honor Society of Nursing, Sigma Theta Tau International Iota Omicron Chapter

2017 - Present

Member, College of Nurses of Ontario (CNO)

General Class

2016 - Present

Graduate Research Assistant (GRA)

Arthur Labatt Family School of Nursing

The University of Western Ontario

Lawson Health Research Institute

January 2017 - Present

\section{Published Abstracts/Presentations:}

Marsella, O., Forchuk, C., \& Oudshoorn, A. (2018, October). Exploring harm reduction among Canadian veterans experiencing homelessness. Poster presentation at the Canadian Institute for Military and Veteran Health Research Forum 2018, Regina, Saskatchewan. 